\title{
Field Performance of Inverter-Driven Heat Pumps in Cold Climates
}

James Williamson and Robb Aldrich Consortium of Advanced Residential Buildings

August 2015 


\section{NOTICE}

This report was prepared as an account of work sponsored by an agency of the United States government. Neither the United States government nor any agency thereof, nor any of their employees, subcontractors, or affiliated partners makes any warranty, express or implied, or assumes any legal liability or responsibility for the accuracy, completeness, or usefulness of any information, apparatus, product, or process disclosed, or represents that its use would not infringe privately owned rights. Reference herein to any specific commercial product, process, or service by trade name, trademark, manufacturer, or otherwise does not necessarily constitute or imply its endorsement, recommendation, or favoring by the United States government or any agency thereof. The views and opinions of authors expressed herein do not necessarily state or reflect those of the United States government or any agency thereof.

Available electronically at http://www.osti.gov/bridge

Available for a processing fee to U.S. Department of Energy and its contractors, in paper, from:

U.S. Department of Energy

Office of Scientific and Technical Information

P.O. Box 62

Oak Ridge, TN 37831-0062

phone: 865.576.8401

fax: 865.576.5728

email: mailto:reports@adonis.osti.gov

Available for sale to the public, in paper, from:

U.S. Department of Commerce

National Technical Information Service

5285 Port Royal Road

Springfield, VA 22161

phone: 800.553 .6847

fax: 703.605.6900

email: orders@ntis.fedworld.gov

online ordering: http://www.ntis.gov/ordering.htm 


\title{
Field Performance of Inverter-Driven Heat Pumps in Cold Climates
}

Prepared for:

The National Renewable Energy Laboratory

On behalf of the U.S. Department of Energy's Building America Program

Office of Energy Efficiency and Renewable Energy

15013 Denver West Parkway

Golden, CO 80401

NREL Contract No. DE-AC36-08GO28308

\author{
Prepared by: \\ James Williamson and Robb Aldrich \\ Consortium of Advanced Residential Buildings \\ Steven Winter Associates, Inc. \\ 61 Washington St \\ Norwalk, CT 06854 \\ NREL Technical Monitor: Stacey Rothgeb \\ Prepared under Subcontract No. KNDJ-0-40342-05
}

August 2015 
The work presented in this report does not represent performance of any product relative to regulated minimum efficiency requirements.

The laboratory and/or field sites used for this work are not certified rating test facilities. The conditions and methods under which products were characterized for this work differ from standard rating conditions, as described.

Because the methods and conditions differ, the reported results are not comparable to rated product performance and should only be used to estimate performance under the measured conditions. 


\section{Contents}

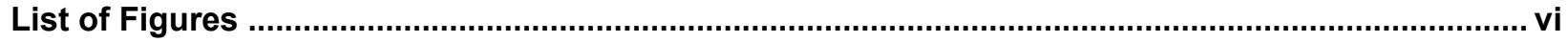

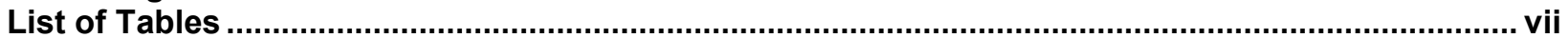

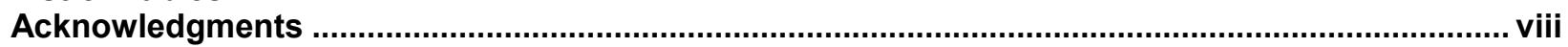

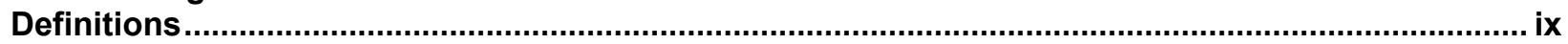

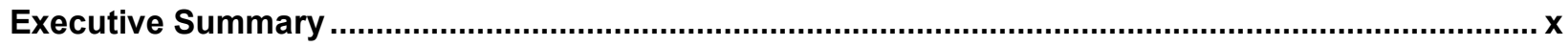

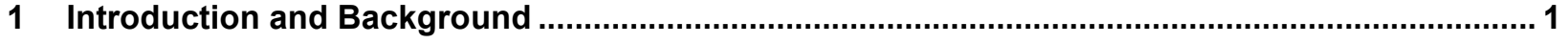

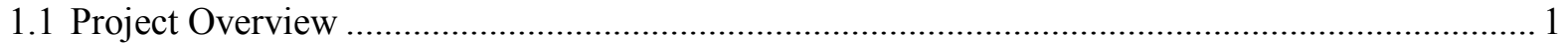

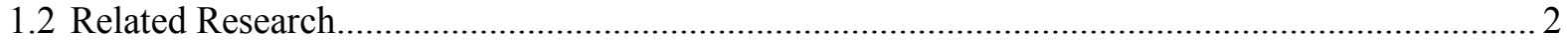

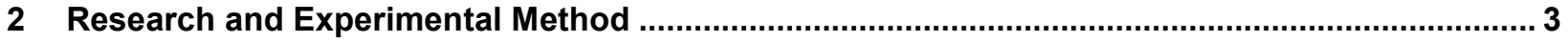

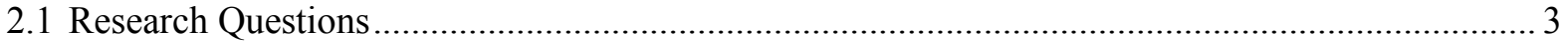

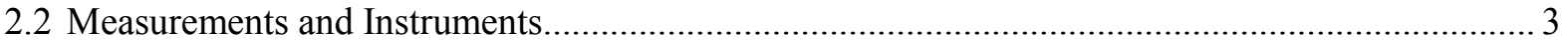

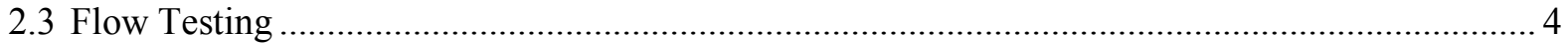

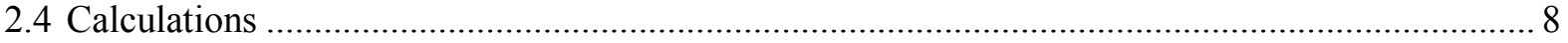

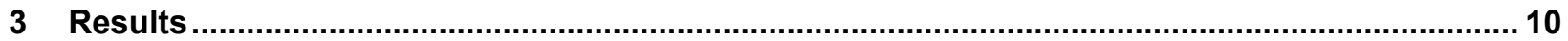

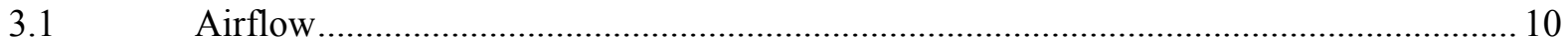

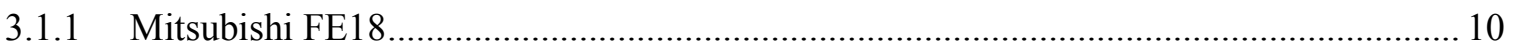

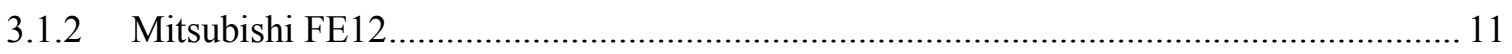

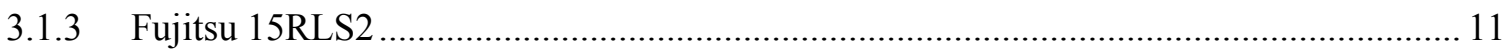

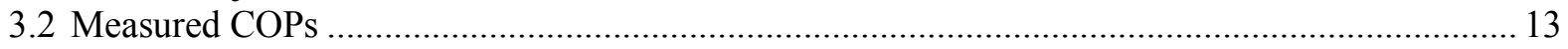

3.2.1 Coefficient of Performance versus Outdoor Air Temperature........................................ 14

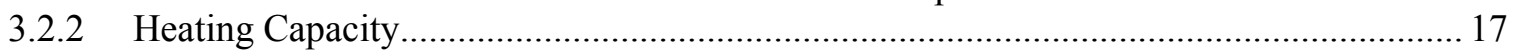

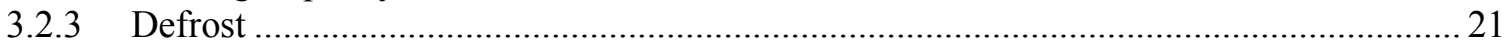

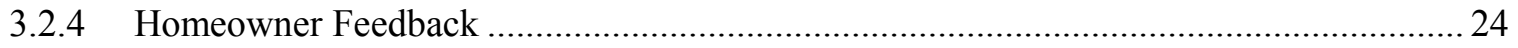

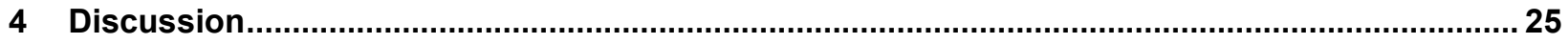

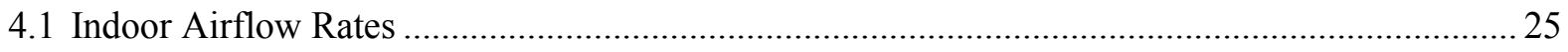

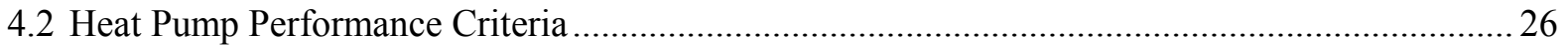

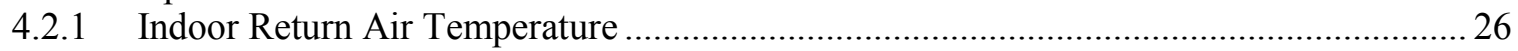

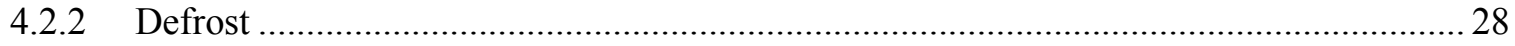

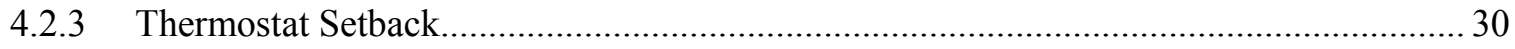

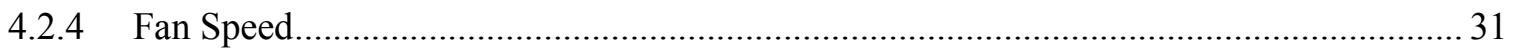

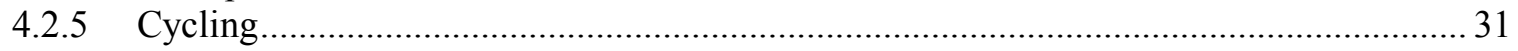

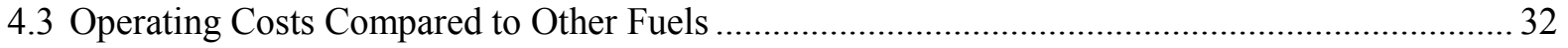

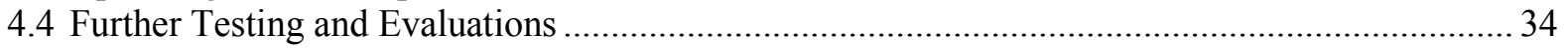

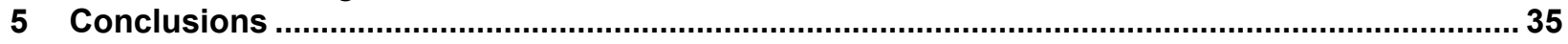

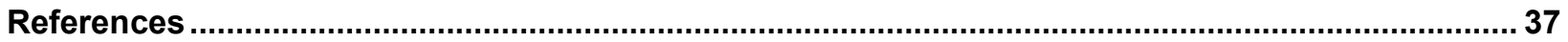




\section{List of Figures}

Figure 1. At left, supply and return temperature sensor locations. The right image shows a close-up of

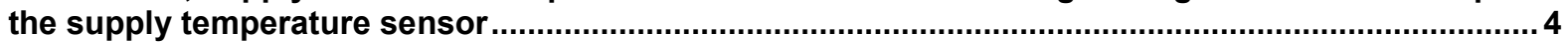

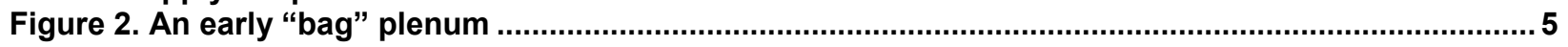

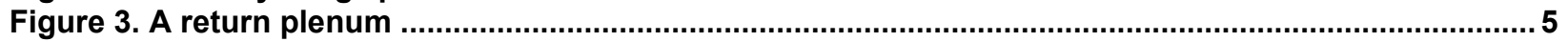

Figure 4. Diagram showing final flow testing configuration .................................................................

Figure 5. Final flow testing configuration ..................................................................................................

Figure 6. Example of flow calibration results at Site 1. The five points at each fan speed represent the five louver positions

Figure 7. FE18 with return leakage pathway taped ................................................................................... 10

Figure 8. FE18 airflow rates: 5 is the highest louver position; 1 is the lowest ...................................... 11

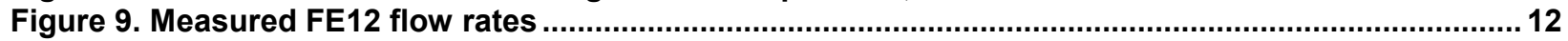

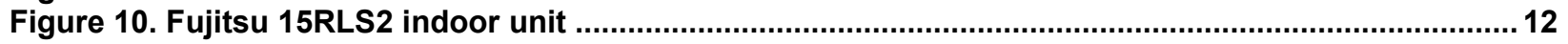

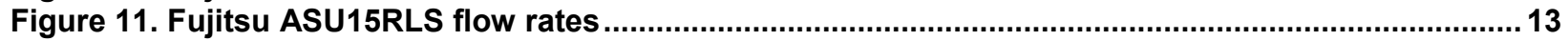

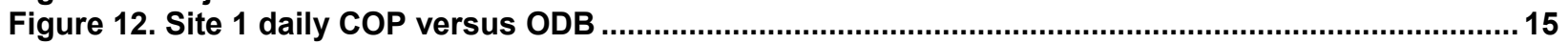

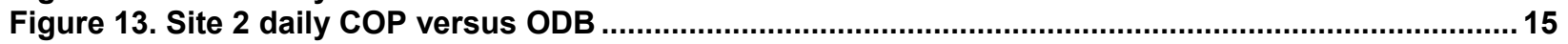

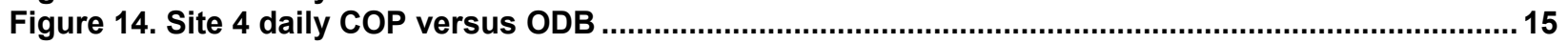

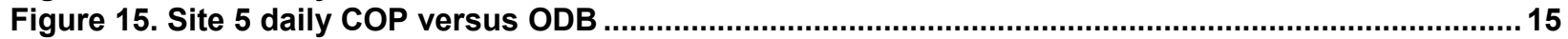

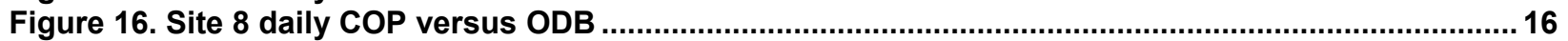

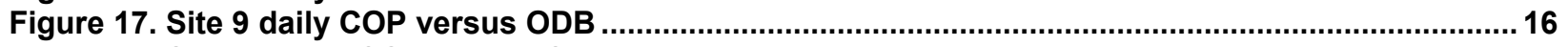

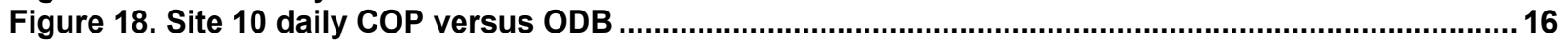

Figure 19. Hourly heat delivered versus outdoor air temperature at Site 4 during January .....................17

Figure 20. Hourly heat delivered versus outdoor air temperature at Site 1 during January ..................... 18

Figure 21. Hourly heat delivered versus outdoor air temperature at Site 2 during February .................... 19

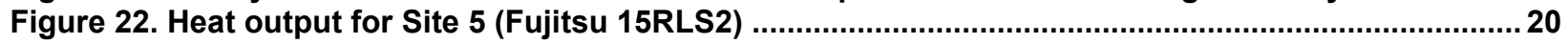

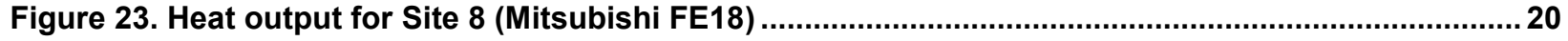

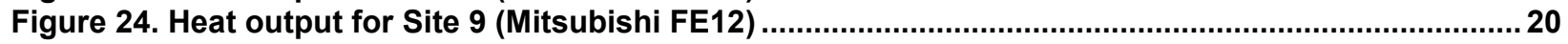

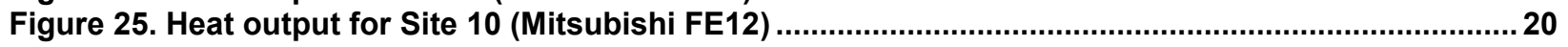

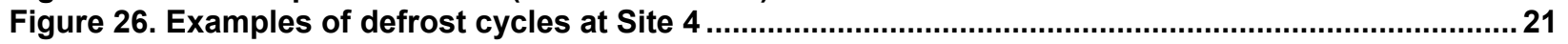

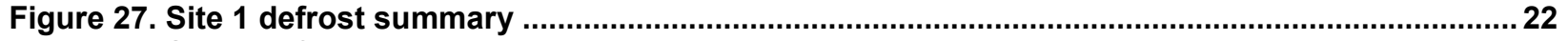

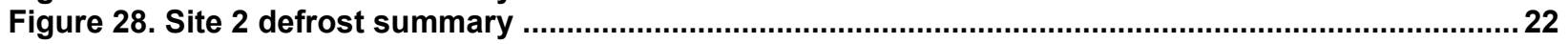

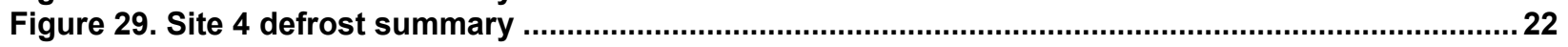

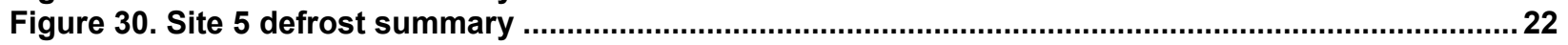

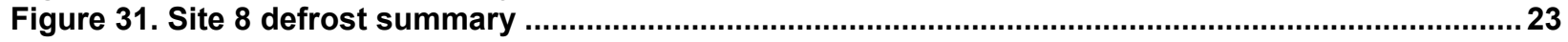

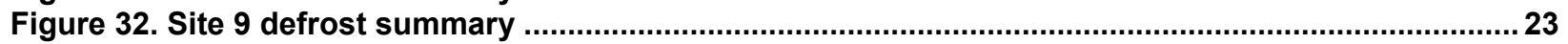

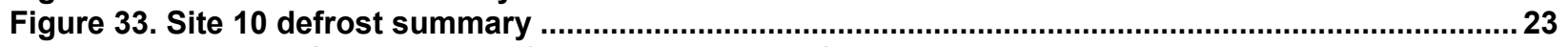

Figure 34. Filters at Site 4 -one before cleaning, one after cleaning ...................................................... 25

Figure 35. Manufacturer data show capacity and efficiency decrease as return air temperatures rise.

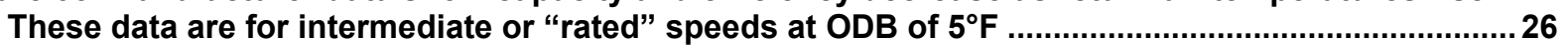

Figure 36. The heat pump at Site 2 was located above a stairway in an area with a vaulted ceiling. This

location may have led to relatively high return air temperatures .........................................................2 27

Figure 37. Visible and infrared images of DHP operation ........................................................................ 28

Figure 38. Snow melting from deck above causes icing and excessive defrost on this heat pump (not

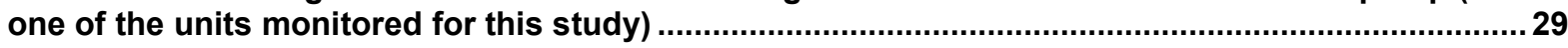

Figure 39. Heat pumps at Site 8. During short-term testing, the lower unit entered defrost mode every 10 minutes; CARB suspects this was largely a result of defrost water from the upper unit refreezing

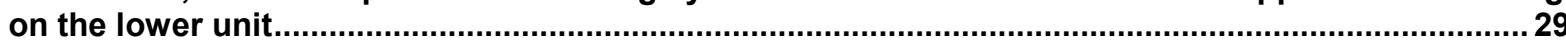

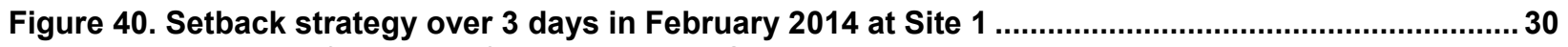

Figure 41. Example of recovery from setback at Site 1 ...................................................................... 31

Figure 42. Cycling during low load conditions at Site 2. Each point represents 1 minute; this is the only time the heat pump operated during this early spring day ................................................................... 32

Unless otherwise indicated, all figures were created by CARB. 


\section{List of Tables}

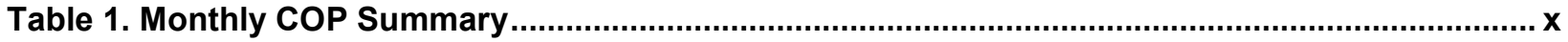

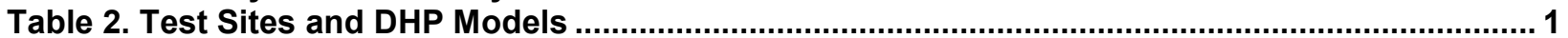

Table 3. Seasonal COP Values from Ecotope's Northwest Study .................................................. 2

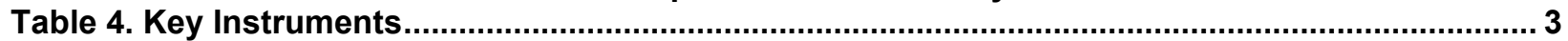

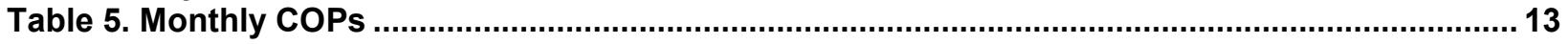

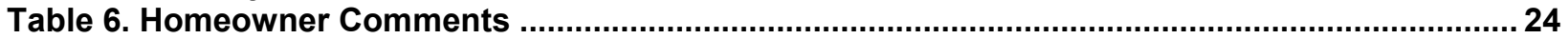

Table 7. Average Return Air Dry Bulb Temperatures ( $\left.{ }^{\circ} \mathrm{F}\right)$ When ASHPs Were Operating ................ 26

Table 8. Overall COP With and Without Defrost Cycles Included......................................................... 30

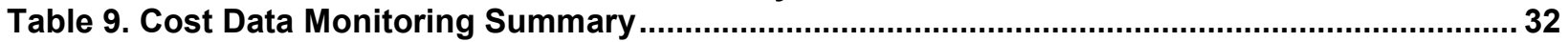

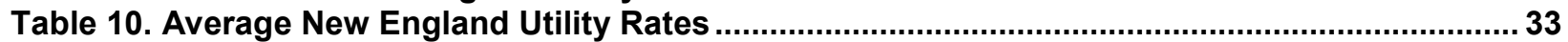

Table 11. Operating Cost Increases (Decreases) of Other Heating Systems Compared to ASHPs

During the Monitoring Period ...................................................................................................... 33

Table 12. Equal-Cost COP Values Based on New England Utility Rates (EIA2014a and EIA2014b) 34

Table 13. Operating Cost Percent Increase (Decrease) Compared to Heat Pump During the Monitoring Period

Unless otherwise indicated, all tables were created by CARB. 


\section{Acknowledgments}

The Consortium of Advanced Residential Buildings (CARB) would like to thank Efficiency Vermont for help in obtaining performance data and test sites throughout Vermont. CARB would also like to thank Mitsubishi Electric, researchers at the National Renewable Energy Laboratory, Ecotope, and the Energy Conservatory for providing guidance on air-source heat pump test methods. Also, thanks to all of the homeowners who participated in the study. 


\section{Definitions}

$\begin{array}{ll}\text { ASHP } & \text { Air-Source Heat Pump } \\ \text { Btu } & \text { British Thermal Unit } \\ \text { Btu/h } & \text { British Thermal Unit per Hour } \\ \text { CARB } & \text { Consortium for Advanced Residential Buildings } \\ \text { COP } & \text { Coefficient of Performance } \\ \text { DHP } & \text { Ductless Heat Pump } \\ \text { kWh } & \text { Kilowatt-Hour } \\ \text { NREL } & \text { National Renewable Energy Laboratory } \\ \text { ODB } & \text { Outdoor Dry Bulb (Temperature) }\end{array}$




\section{Executive Summary}

Traditionally, air-source heat pumps (ASHPs) have been used more often in warmer climates; however, some new ASHPs are gaining ground in colder areas. These systems operate at subzero (Fahrenheit) temperatures and many do not include backup electric resistance elements. There are still uncertainties, however, about capacity and efficiency in cold weather. Also, questions such as "how cold is too cold?" do not have clear answers. These uncertainties could lead to skepticism among homeowners; poor energy savings estimates; suboptimal system selection by heating, ventilating, and air-conditioning contractors; and inconsistent energy modeling.

In an effort to better understand and characterize the heating performance of these units in cold climates, the U.S. Department of Energy Building America team, Consortium for Advanced Residential Buildings (CARB), monitored seven inverter-driven, ductless ASHPs across the Northeast. Operating data were collected for three Mitsubishi FE18 units, three Mitsubishi FE12 units, and one Fujitsu 15RLS2 unit. The intent of this research was to assess heat output, electricity consumption, and coefficients of performance (COPs) at various temperatures and load conditions. This assessment was accomplished with long- and short-term tests that measured power consumption; supply, return, and outdoor air temperatures; and airflow through the indoor fan coil.

Airflow measurements made use of a large, fan-assisted flow hood over the supply of each ductless heat pump. A large plenum (typically a cube of approximately 3 or $4 \mathrm{ft}$ ) was constructed from rigid foam. This plenum was kept at zero pressure (with respect to the room) with a variable-speed Duct Blaster fan. Airflow rate was measured using this same fan. The measured flow rates were much lower than expected - typically $50 \%-80 \%$ of rates listed by manufacturers.

Table 1 shows a summary of monthly COPs observed at each site. Researchers observed a wide range of operating efficiencies and outputs at the various sites. Generally, maximum capacities were in line with manufacturers' claims at low temperatures $\left(0^{\circ} \mathrm{F}\right.$ or lower $)$.

Table 1. Monthly COP Summary

\begin{tabular}{c|c|c|c|c|c|c|c}
\hline Month & Site 1 & Site 2 & Site 4 & Site 5 & Site 8 & Site 9 & Site 10 \\
\hline Nov 2013 & 1.3 & - & - & - & - & - & - \\
\hline Dec 2013 & 1.6 & - & 2.3 & - & - & - & - \\
Jan 2014 & 1.4 & 2.0 & 2.4 & - & - & - & - \\
\hline Feb 2014 & 1.6 & 1.9 & 2.2 & 1.8 & - & - & - \\
Mar 2014 & 1.8 & 2.0 & 2.3 & 1.7 & 2.2 & 1.0 & 1.8 \\
April 2014 & 2.2 & 1.9 & 3.1 & - & 2.5 & 1.3 & 2.4 \\
Overall & 1.6 & 2.0 & 2.3 & 1.7 & 2.3 & 1.1 & 2.1 \\
\hline
\end{tabular}

The reasons for the wide range in heating performance likely include low indoor airflow rates, poor placement of outdoor units, relatively high return air temperatures, thermostat setback, integration with existing heating systems, and occupants limiting indoor fan speed. Even with lower efficiencies than published in other studies, most of the heat pumps still provided heat at a lower cost than oil, propane, or electric resistance systems. 


\section{Introduction and Background}

\subsection{Project Overview}

In a growing trend, inverter-driven ASHPs are being installed in many cold-climate homes (NEEP 2013). Technology advances allow units to operate at subzero temperatures without electric resistance backup. With a growing number of installations, there is an increased need for field monitoring to determine how effectively ASHPs are operating in cold climates. Through funding from the U.S. Department of Energy's Building America Program and a partnership with Efficiency Vermont, the Consortium for Advanced Residential Buildings (CARB) monitored heating performance of several ductless heat pumps (DHPs) in several homes across the Northeast during the winter of 2013-2014.

All of the systems monitored were split DHPs. Each system consists of a single outdoor unit (containing the compressor and outdoor heat exchanger) and an indoor fan coil. Refrigerant piping and wiring run between the two main components. Each system has its own control system (typically with a handheld remote interface) that is separate from the controls of other heating systems in the home.

In total, CARB examined 10 DHPs for this study. Table 2 shows each of the test site locations, the heat pump manufacturer and model, and notes about each location. Most of this research was completed through a partnership with Efficiency Vermont. Initially, 10 sites were fitted with monitoring equipment and underwent airflow testing. Three of the Vermont sites $(3,6$, and 7$)$ did not provide usable data because of problems with the monitoring equipment.

Table 2. Test Sites and DHP Models

\begin{tabular}{|c|c|c|c|}
\hline Site & Location & Heat Pump & Notes \\
\hline 1 & Shelburne Falls, MA & Mitsubishi FE18 & $\begin{array}{c}\text { 100+ year-old farmhouse. ASHP supplements } \\
\text { hydronic oil system. }\end{array}$ \\
\hline 2 & Danbury, CT & Mitsubishi FE12 & $\begin{array}{c}\text { New construction, Passive House certified. ASHP is } \\
\text { only heat source. }\end{array}$ \\
\hline 3 & Burlington, VT & Mitsubishi FE18 & $\begin{array}{l}\text { Apartment in } 50-100 \text { year-old home. ASHP } \\
\text { supplements hydronic oil system. }\end{array}$ \\
\hline 4 & Jericho, VT & Mitsubishi FE18 & $\begin{array}{l}\text { House undergoing deep energy retrofit. ASHP is the } \\
\text { primary, if not the only, source of heat during } \\
\text { monitoring period. }\end{array}$ \\
\hline 5 & Jericho, VT & Fujitsu 15RLS2 & $\begin{array}{l}\text { Approximately } 20 \text { year-old home. ASHP } \\
\text { supplements hydronic oil system. }\end{array}$ \\
\hline 6 & Westford, VT & Mitsubishi FE18 & $\begin{array}{l}\text { 50-100 year-old home. ASHP supplements hydronic } \\
\text { oil system. }\end{array}$ \\
\hline 7 & Thetford, VT & Mitsubishi FE12 & $\begin{array}{l}\text { Approximately } 100 \text { year-old home. ASHP } \\
\text { supplements hydronic oil system. }\end{array}$ \\
\hline 8 & Pawlet, VT & Mitsubishi FE18 & $\begin{array}{c}\text { 20-30 year-old home. ASHP supplements hydronic } \\
\text { oil system. }\end{array}$ \\
\hline 9 & Wallingford, VT & Mitsubishi FE12 & $\begin{array}{l}\text { Approximately } 100 \text { year-old home. ASHP } \\
\text { supplements forced-air oil heating system. }\end{array}$ \\
\hline 10 & Rutland, VT & Mitsubishi FE12 & $\begin{array}{l}\text { 50-100 year-old home. ASHP supplements hydronic } \\
\text { oil system. }\end{array}$ \\
\hline
\end{tabular}


Most of these systems were installed to displace fossil fuel heating systems in homes; however, Site 2 and Site 4 used the DHPs as their primary heat source. Home construction and building loads varied greatly among test sites. For instance, Site 1 was a renovated farmhouse built in the late 1800s while Site 2 was new construction that achieved Passive House certification. The wide array of building types and heating scenarios allowed the study to capture a variety of coldclimate heating applications.

\subsection{Related Research}

Prior to this research CARB examined several past studies of ASHP performance. In a field monitoring evaluation that took place from 2009-2012, Ecotope monitored the heating performance of DHPs in homes in Idaho and Montana (climate zones 5 and 6, ICC 2009). These homes all used DHPs as supplemental heating sources. Most models investigated in this study were Mitsubishi FE12 units. A summary of average heating COPs from this monitoring study is shown in Table 3 (Baylon et al. 2012).

Table 3. Seasonal COP Values from Ecotope's Northwest Study

\begin{tabular}{c|c|c}
\hline Site & Number of Sites & Average Heating COP \\
\hline Montana & 6 & 3.16 \\
\hline Eastern Idaho (Bonneville Power Administration) & 4 & 3.07 \\
\hline Eastern Idaho (Northwest Energy Efficiency Alliance) & 6 & 2.81 \\
Average & 16 & 3.01 \\
\hline
\end{tabular}

From November 2009 through March 2011, Connecticut Light \& Power researchers monitored the performance of a Fujitsu AOU9RLQ in a 550-square foot $\left(\mathrm{ft}^{2}\right)$ apartment in Middletown, Connecticut. Average heat pump COP was estimated to be 2.9 using coheating tests (i.e., alternating between electric resistance and DHP operation). It is important to note that there were some periods during this test where the heat pump was unable to meet the entire load (Bugbee and Swift 2013).

In a study that took place from 2009-2011, CARB investigated the performance of a twocompressor, low-temperature ASHP (the Acadia made by Hallowell Industries) installed in New Haven, Connecticut. Seasonal COPs were 3.29 during winter 2009-2010 and 2.68 during winter 2010-2011. Aside from a few maintenance setbacks, the equipment operated effectively in cold temperatures and mostly aligned with listed performance from the manufacturer at the observed outdoor temperatures $\left(12^{\circ}-47^{\circ} \mathrm{F}\right)$. This particular technology differs from inverter-driven, variable-speed ASHPs on the market now, and it is no longer manufactured (Johnson 2013).

In 2009, KEMA, Inc. evaluated DHP pilot programs for Massachusetts and Connecticut utilities (KEMA 2009). The study documented savings when DHPs were installed in homes to offset electric resistance heating. In 124 Connecticut homes, average annual energy reductions were approximately 2,700 kilowatt-hours per year ( $\mathrm{kWh} /$ year) (this may have included some increase in cooling energy). There was also a very high variability in savings from nearly 12,000 $\mathrm{kWh} /$ year to a net increase of more than $4,000 \mathrm{kWh} /$ year. 


\section{Research and Experimental Method}

\subsection{Research Questions}

This study was intended to address the following research questions as they relate to homes in climate zones 5 and 6 :

- What heating output, electricity use, and COP, do the ASHPs deliver in the field? How do these vary with outdoor temperatures and loads?

- How does cycling affect efficiency during mild outdoor conditions?

- How do varying thermostat set points affect efficiency (e.g., frequent setup and setback may lead to higher operating speeds and lower efficiencies)?

- What level of savings can be expected over other fuels?

\subsection{Measurements and Instruments}

The test and evaluation methods were based on the National Renewable Energy Laboratory's (NREL) report, Field Monitoring Protocol: Mini-Split Heat Pumps (Christensen et al. 2011). The monitoring setup involved fitting sensors and data acquisition systems on several heat pumps in homes across the Northeast. Table 4 lists the measurements and equipment used at each of the 10 test sites.

Table 4. Key Instruments

\begin{tabular}{c|c|c}
\hline Measurement & Instrument/Equipment & Accuracy \\
\hline $\begin{array}{c}\text { Return Air Temperature and } \\
\text { Relative Humidity }\end{array}$ & Powerwise DS18B20 & $\begin{array}{c} \pm 0.6^{\circ} \mathrm{F} \\
\pm 3 \% \text { relative } \\
\text { humidity }\end{array}$ \\
Supply Air Temperature & Powerwise DS18B20 (three at each site) & $\pm 0.6^{\circ} \mathrm{F}$ \\
Power Consumption & Powerhouse Dynamics eMonitor & $\pm 2 \%$ of reading \\
\hline Airflow & $\begin{array}{c}\text { Energy Conservatory model B Duct Blaster } \\
\text { with DG-700 Manometer }\end{array}$ & $\pm 3 \%$ of reading \\
\hline Indoor Fan Coil Current & AccuAmp ACTR005-42L-F & $\pm 0.02 \mathrm{~A}$ \\
\hline
\end{tabular}

Power measurements were made with Powerhouse Dynamics' eMonitor system. The eMonitor was installed in the electric panel. The eMonitor gateway was located near the panel and communicated through the home's network.

Temperature sensors were installed at both the supply and return grilles on the indoor fan coils. Figure 1 shows the location of the installed sensors. Supply sensors were attached behind the supply louvers against the fan guard. In order to correct for varying supply air temperatures, three measurements were taken and averaged across the horizontal length of the supply stream. The return temperature and relative humidity sensor was simply mounted on top of the indoor unit near the center of the return grille. The entering airstream was assumed to be well mixed. A single measurement was used here. 
A current transducer was installed in each fan coil to measure electrical current; this current measurement was used to assess system flow rate (this is described in more detail in Section 2.3). The temperature and humidity sensors and current transducer were attached to a PowerWise inDAC that communicated wirelessly to the eMonitor gateway. Sensor measurements were made at 1 -second intervals and data were stored every minute as sums or averages (as appropriate).
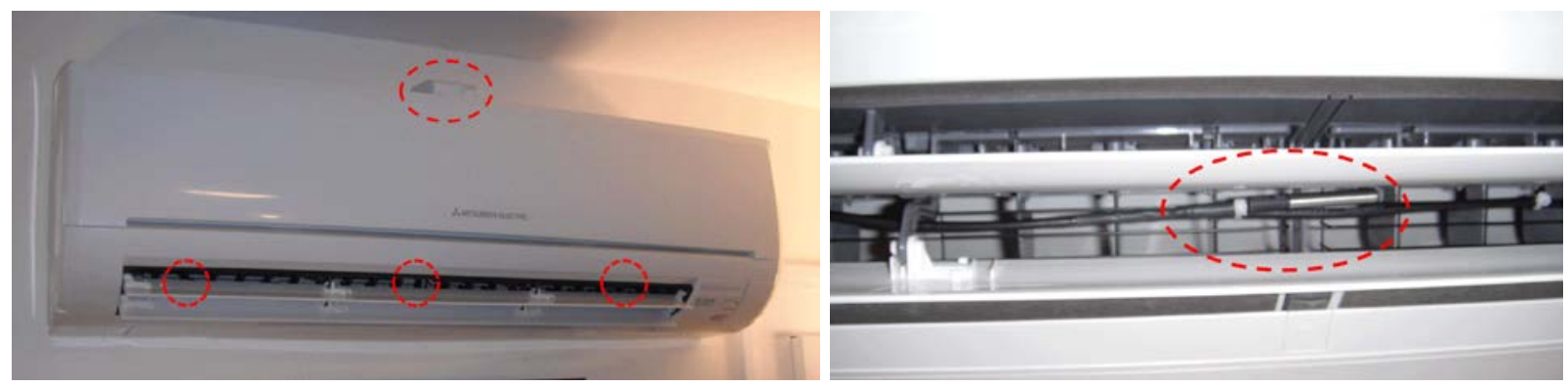

Figure 1. At left, supply and return temperature sensor locations. The right image shows a close-up of the supply temperature sensor

At Sites 1 and 2, CARB installed all instrumentation. At Sites 3-10, Efficiency Vermont installed the monitoring systems. CARB visited all 10 sites to perform airflow testing and current/flow calibration.

\subsection{Flow Testing}

The airflow testing procedure used on the indoor fan coils was based on the procedure published by NREL (Christensen et al. 2011). In principle, the test consists of the following steps:

1. Construct a sealed hood or plenum around the fan coil supply.

2. Install static pressure probe(s) within this plenum.

3. Attach a variable speed fan with integral flow measurement (in this case a Minneapolis Duct Blaster) to the plenum.

4. Turn on the heat pump while controlling the duct blaster to maintain zero static pressure within the plenum.

5. Measure airflow through the duct blaster (which is equal to flow through the fan coil).

The premise is that the fan-assisted flow hood does not add any pressure or restriction to airflow; it is meant to simulate the fan coil blowing into the room without any obstructions.

In practice, there were many iterations of the flow testing procedure. The homeowner at Site 1 (who worked in the energy efficiency field and was very interested in results) allowed CARB to visit his home five times to adjust and refine the procedure. The various methods included using a plastic bag plenum (Figure 2), building a plenum on the return rather than on the supply (Figure 3), and using hot wire and vane anemometers to measure velocity at the return grille. CARB revisited this procedure several times because measured flow rates were significantly lower than those listed by manufacturers and published in laboratory tests (Winkler 2011). 


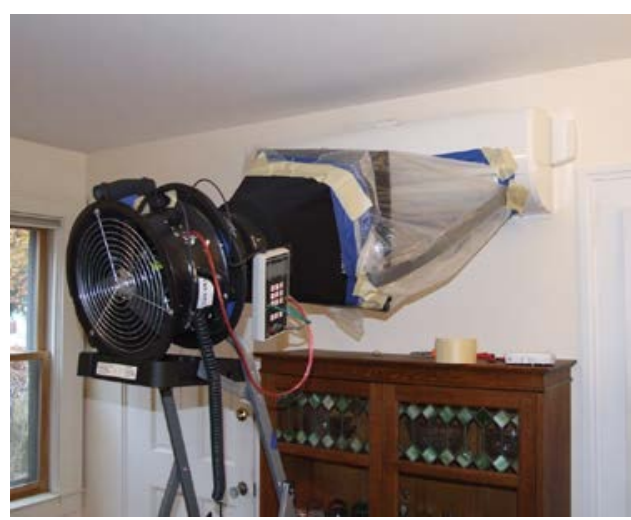

Figure 2. An early "bag" plenum

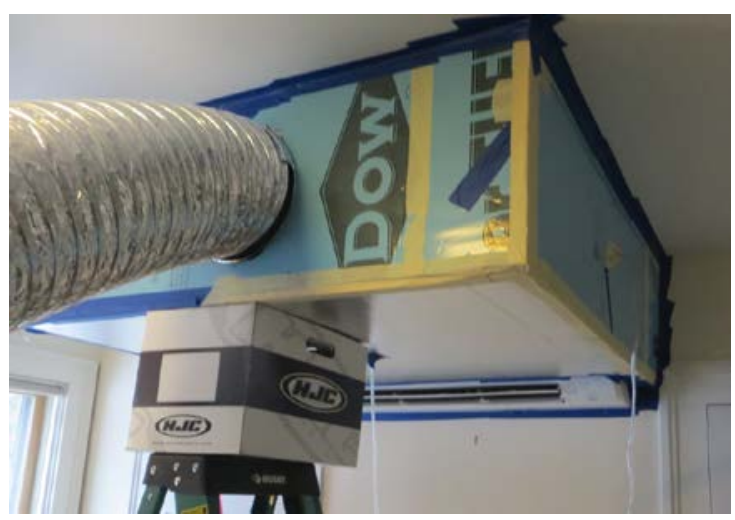

Figure 3. A return plenum

To improve the procedure and to try to account for these discrepancies, researchers contacted other building scientists at NREL, Ecotope, Florida Solar Energy Center, The Energy Conservatory, and others. These experts provided valuable feedback and suggestions. CARB also contacted engineers at Mitsubishi Electric, and a Mitsubishi engineer visited Site 1 with CARB on the last round of flow testing at that site.

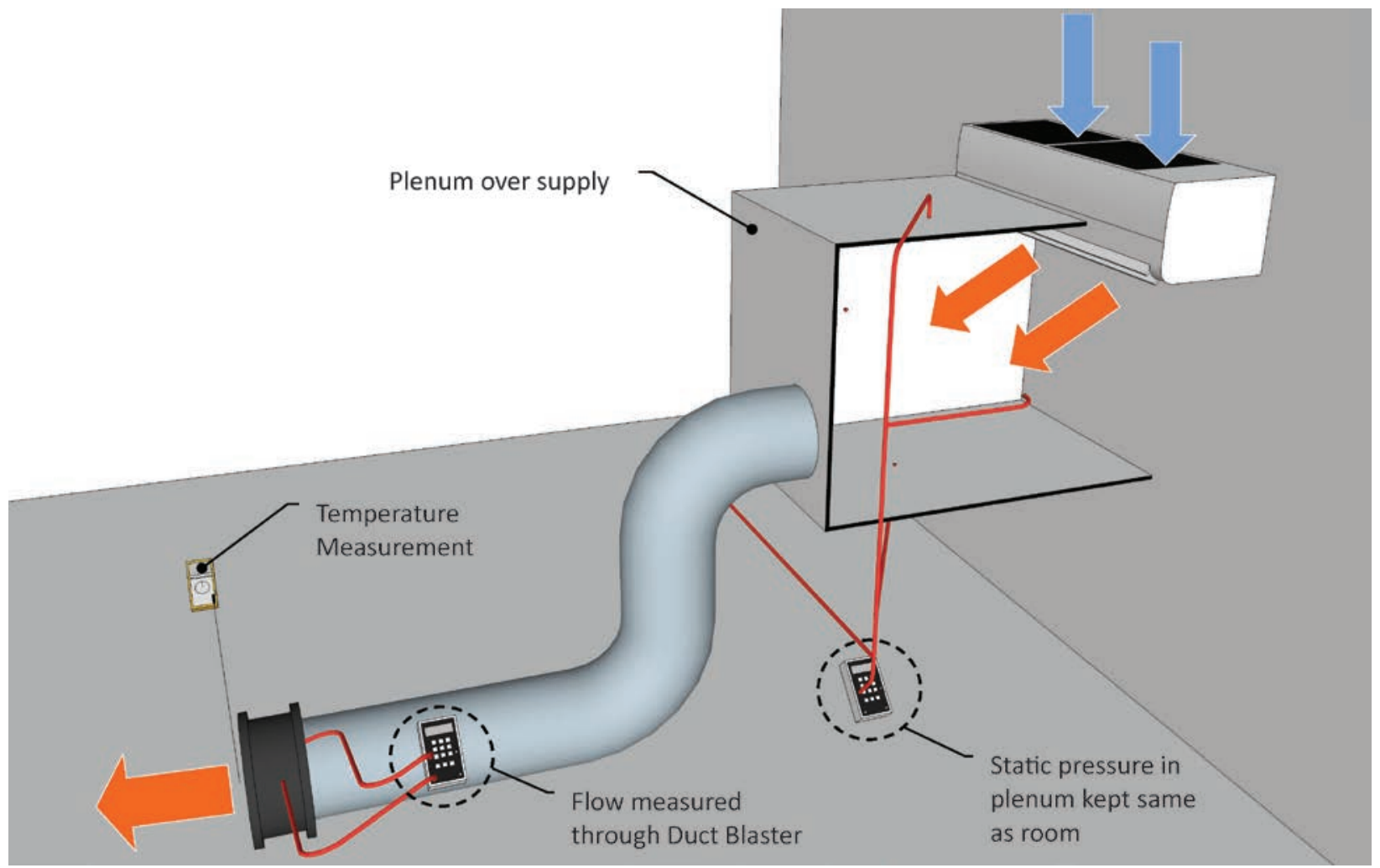

Figure 4. Diagram showing final flow testing configuration

The final procedure for flow measurement follows:

1. Turn off the heat pump.

2. Inspect the filters and clean them if necessary. Shake dry as much as possible. 
3. Install a tube under the filter (between the filter and the coil) to measure return static pressure.

4. In normal operation, run the heat pump at each fan speed and louver position. Record:

○ Return static pressure

- Fan coil current (as described above).

5. Tape the edges of the filter access flap and any other return leakage pathways.

6. Construct a large rigid plenum (1/2-inch (in.) rigid foam board and masking tape were the most convenient materials) to go over the fan coil supply. Plenums were generally 3 -ft or 4-ft cubes, though geometry varied with site constraints. Leave the return grille open to the room.

7. Put the plenum in place and support with ladders, etc.

8. Tape all edges where the plenum meets the wall and the fan coil.

9. Cut a small viewing pane in the plenum and cover with clear tape (to see louver positions and for remote control).

10. Attach the blower with a length of flexible duct. Install proper flow ring, flow conditioner, and pressure connections as appropriate per Minneapolis Duct Blaster instructions.

11. Install a static pressure reference tap in the center of each face of the cube (top, bottom, left, right). These are connected together and used as the reference pressure for Duct Blaster control.

12. Install a temperature sensor at the Duct Blaster outlet.

13. Operate the heat pump at each fan speed and each louver position. Record:

- Return static pressure

○ Fan coil current

○ Flow rate through Duct Blaster

○ Temperature of air through the Duct Blaster.

The final test configuration is shown in Figure 4 and Figure 5. Using air temperature and site elevation, flow rates were converted to standard cubic feet per minute (SCFM) at air density of 0.075 cubic foot $\left(\mathrm{lb}_{\mathrm{m}} / \mathrm{ft}^{3}\right)$. Flow rates were then plotted against current at each fan speed as shown in Figure 6. 


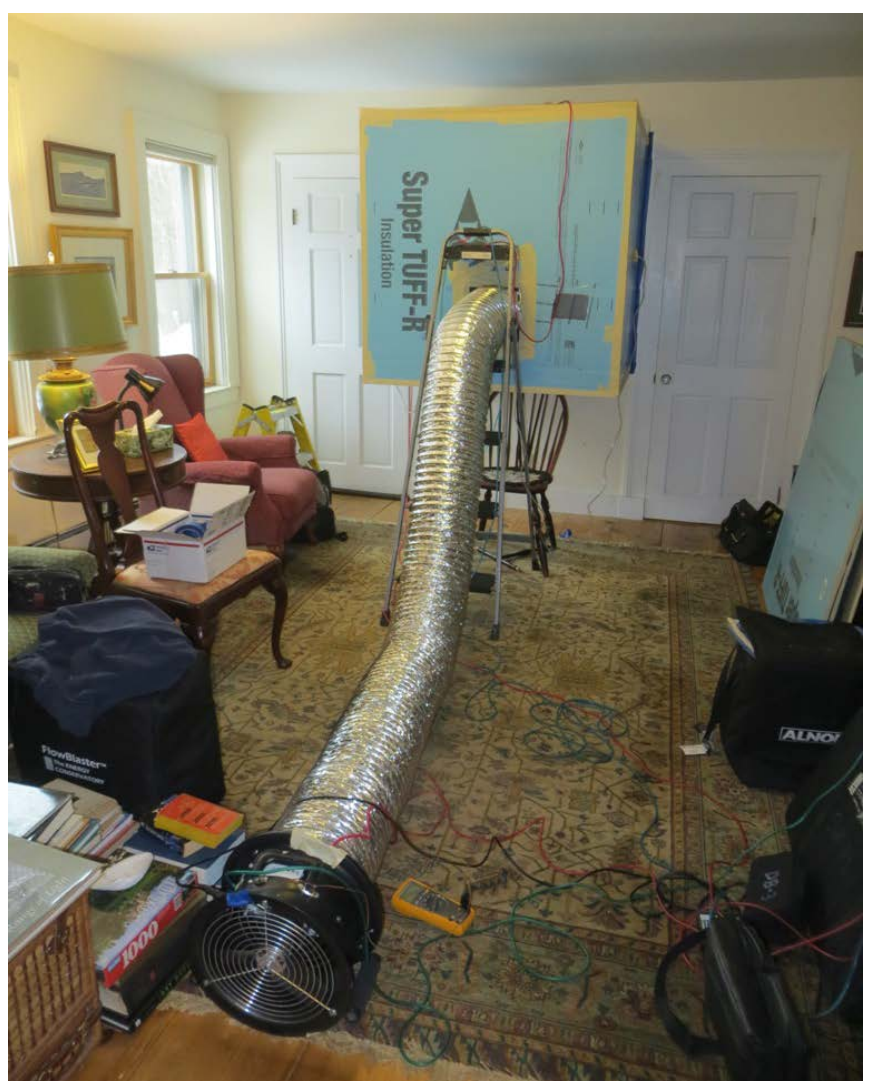

Figure 5. Final flow testing configuration

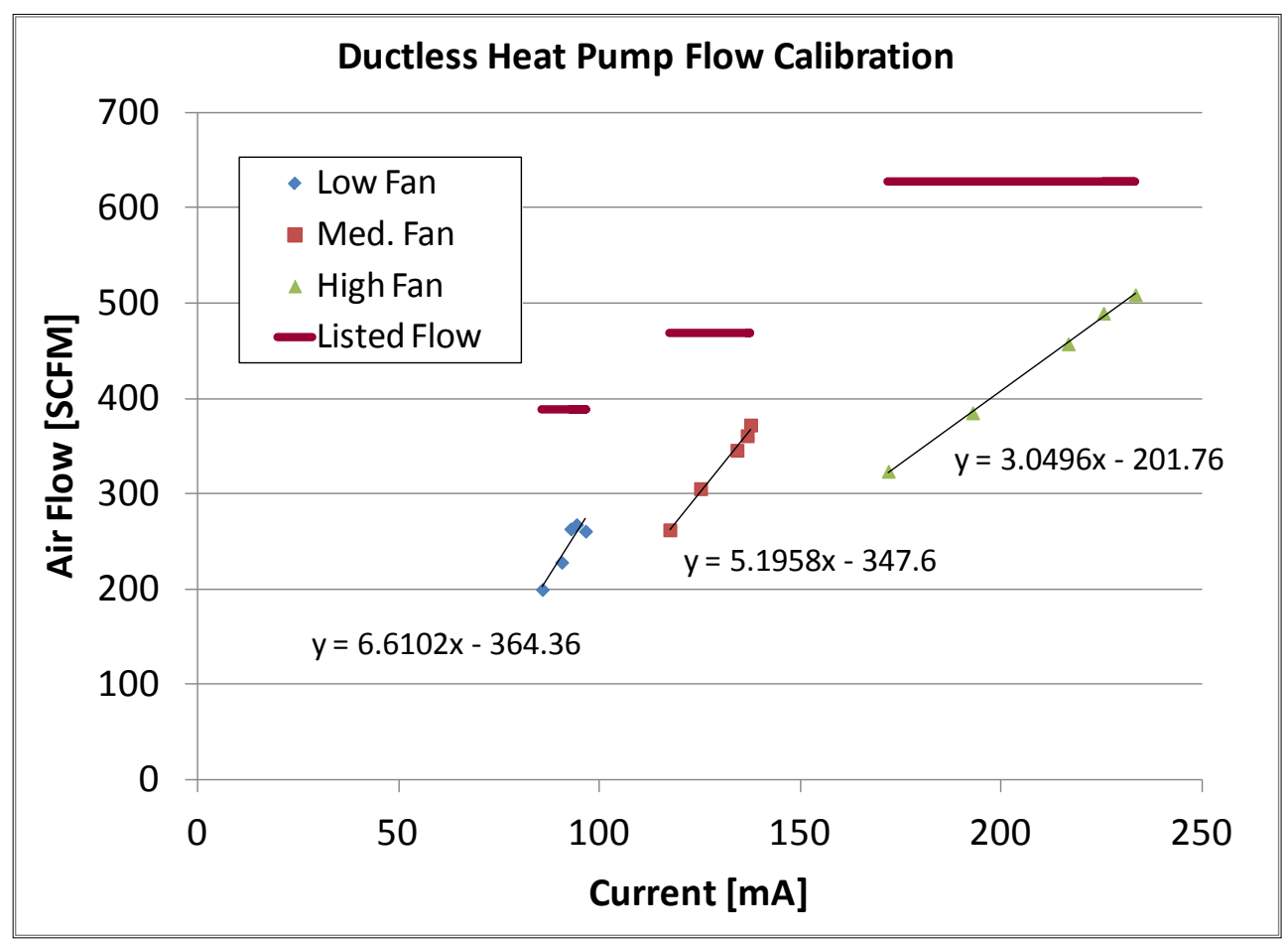

Figure 6. Example of flow calibration results at Site 1.

The five points at each fan speed represent the five louver positions 
Figure 6 shows that various louver positions led to very different flow rates. Also, flow rates were significantly lower than rates published by the manufacturer (approximately $50 \%-80 \%$ of published flow rates). This was concerning, because CARB could find no precedent for similar results in published studies. This discrepancy led to the following tests:

Return Bypasses. As described in the Results section, there was sometimes potential for air to leak from the constructed supply plenum back into the DHP's return air pathway. When this bypass was identified and sealed, measured flow rates in FE18 systems were slightly higher (though there was no effect in other models tested). To check for the presence of other return air bypasses, CARB constructed the supply plenums 2 in. from the wall and sealed the plenum to the bottom of the fan coil. The purpose was to mitigate the potential for return leakage from behind the fan coil; however, measured flow rates were identical to those from tests where the plenum was attached directly to the wall.

Location of Pressure Sensors. The final test procedure included measuring average supply static pressure at the center of each face of the cubic supply plenum. This static pressure was controlled to be equal to the pressure in the room. CARB experimented with moving these sensors within the plenum - including directly in the air stream from the fan coil — but there were no measurable pressure differences within the plenum.

Return Static Pressure. As described above, the ultimate test method involved measuring return static pressures at each fan speed and louver position both with and without the plenum attached. Return static pressures ranged from approximately 3 Pascals $(\mathrm{Pa})$ at low speed to $11 \mathrm{~Pa}$ at high fan speed. Differences in pressure with and without the plenum were very small. The average absolute difference at all sites was less than $0.5 \mathrm{~Pa}$; the largest difference observed was $1.5 \mathrm{~Pa}$ at high speed. There was not a consistent direction in the difference, i.e., sometimes return static pressures were higher with the plenum and sometimes they were higher without the plenum. Steven Winters Associates' conclusion from this was that the fan-assisted flow plenum was not significantly affecting the normal flow characteristics of the fan coil.

Return Velocity. At several sites, CARB measured air velocity at the face of the return grilles with hot wire or vane anemometers. The purpose here was similar to the return static pressure tests: assess differences in velocity between normal operation and with the flow hood attached. Velocity differences were negligible; the differences were much smaller than the listed accuracy of the anemometers.

\subsection{Calculations}

Heat output of the heat pump was calculated using:

$$
\dot{\mathrm{Q}}=\dot{\mathrm{mc}} \mathrm{p} \Delta \mathrm{T}
$$

where:

$\dot{\mathrm{Q}}$ is the rate at which the heat pump supplies heat to the building in British thermal unit per hour $(\mathrm{Btu} / \mathrm{h})$

$\mathrm{C}_{\mathrm{p}}$ is the heat capacity of air as a function of temperature in $\mathrm{Btu} / \mathrm{lb}_{\mathrm{m}}{ }^{\circ} \mathrm{F}$ 
$\Delta \mathrm{T}$ is the temperature difference between heat pumps supply and return air in ${ }^{\circ} \mathrm{F}$

$\dot{\mathrm{m}}$ is mass flow rate of air in $\mathrm{lb} / \mathrm{hr}$. For long term monitoring, this was determined from fan current draw using a fan power flow curve. Mass flow was calculated as product of density $(\rho) \mathrm{lb} / \mathrm{ft}^{3}$ in and volumetric flow rate $\dot{V}$ in $\mathrm{ft}^{3} / \mathrm{min}$.

Uncertainty in heat delivered was calculated using the root sum of the squares of the relative uncertainties shown in Table 4. Mainly because of the uncertainty associated with the fan coil current transducer used as a proxy for airflow, the typical uncertainty in rate of heat delivered was approximately $\pm 20 \%$.

The COP was calculated as heat output over electricity consumption for a given period as follows

$$
C O P=\frac{Q}{E} \times \frac{K W H}{3412 B T U}
$$

where:

$\mathrm{Q}$ is the heat output over a given period in Btu

$\mathrm{E}$ is the electrical energy consumed over the same period in $\mathrm{kWh}$

Again, primarily because of the accuracy limitations associated with current and flow measurement, $\pm 21 \%$ uncertainty in COP calculations was typical. 


\section{Results}

\subsection{Airflow}

CARB examined three models of DHPs: Mitsubishi FE18, Mitsubishi FE12, and Fujitsu 15RLS2. Results of flow testing for each of these units are outlined below.

\subsubsection{Mitsubishi FE18}

The most prevalent heat pump model in the study was the Mitsubishi FE18. Initially, CARB tested each unit with the rigid plenum supply method. Flow rates measured were consistent with each other but well below the published values. In an effort to understand this discrepancy, CARB discussed this with other researchers, equipment manufacturers, and Mitsubishi engineers. As part of the troubleshooting effort, CARB repeated the flow measurement test with help from a Mitsubishi engineer at Site 1. During this test, a return leakage pathway was discovered through the filter cover. When the plenum was installed, it was possible for air inside the plenum to be drawn into the seam of the filter flap. By repeating the flow test with this pathway taped off (Figure 7), measured flow rates increased slightly.

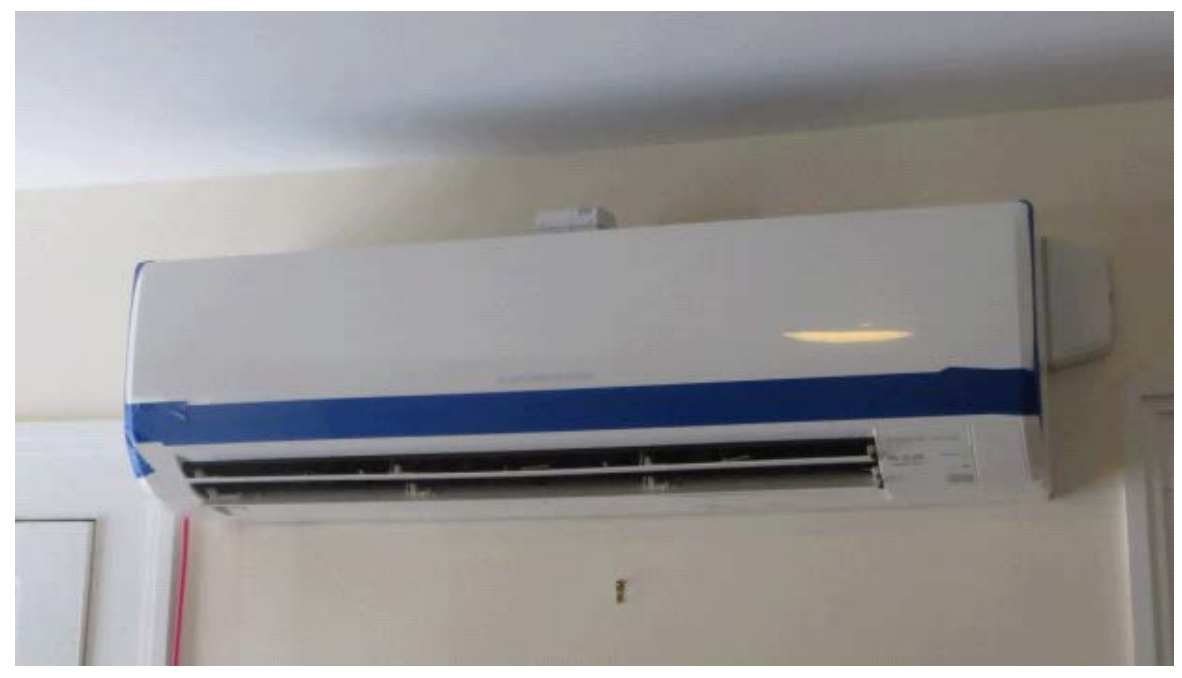

Figure 7. FE18 with return leakage pathway taped

Flow results from the Mitsubishi FE18s at various fan speeds and louver positions are shown in Figure 8. At Site 1 (where the return leakage pathway was taped during testing) flow rates are slightly higher than at other sites. CARB does not believe that taping this leakage pathway affected "normal" airflow rates through the fan coil for two reasons:

- The area of the bypass is extremely small compared to the return grille

- CARB measured no difference in return static pressure (measured beneath the filter) with and without the return pathway taped.

This bypass was discovered after flow testing was completed for all other sites. As it was not feasible to retest all sites, CARB had to assume that flow rates through all FE18 units were similar to flow rates at Site 1. Current-flow correlations at each site used site-specific current measurements with flow rates from Site 1 . This is certainly not ideal, but as measured flow rates 
in all systems with the bypass were very similar to each other, it is assumed that these similarities would remain when the leakage pathway had been taped.

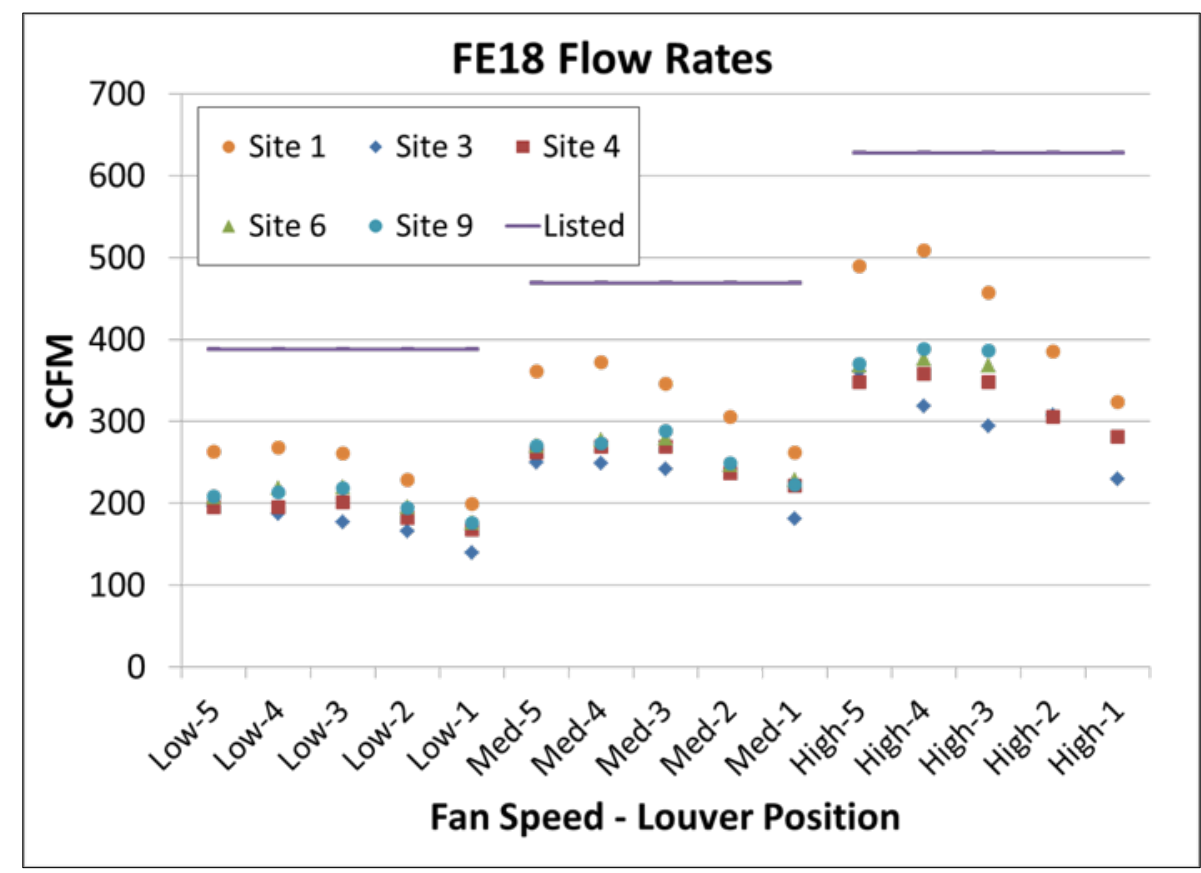

Figure 8. FE18 airflow rates: 5 is the highest louver position; 1 is the lowest

\subsubsection{Mitsubishi FE12}

CARB originally tested each FE12 unit with the rigid foam plenum supply method. After learning of the leakage pathway in the FE 18 model, CARB visited the FE12 at Site 2. After taping the filter slot, flow values were unchanged, indicating that the FE12 does not contain this return leakage pathway. Again, maximum field-measured flow rates were approximately $75 \%$ of the listed flow rates. The flow rates found from FE12 units are shown in Figure 9.

\subsubsection{Fujitsu 15RLS2}

One heat pump tested was a Fujitsu 15RLS2. An image of the unit while operating is shown in Figure 10; note the front face is elevated during operation. The flow measurement process differed slightly from the process for Mitsubishi units. The mechanics and geometry of this unit complicated mounting of the supply plenum. CARB could not attach the plenum until the fan coil was operating (and therefore open). All visible leakage points were taped; however, the complex geometry made leaks and/or bypasses more difficult to identify. 


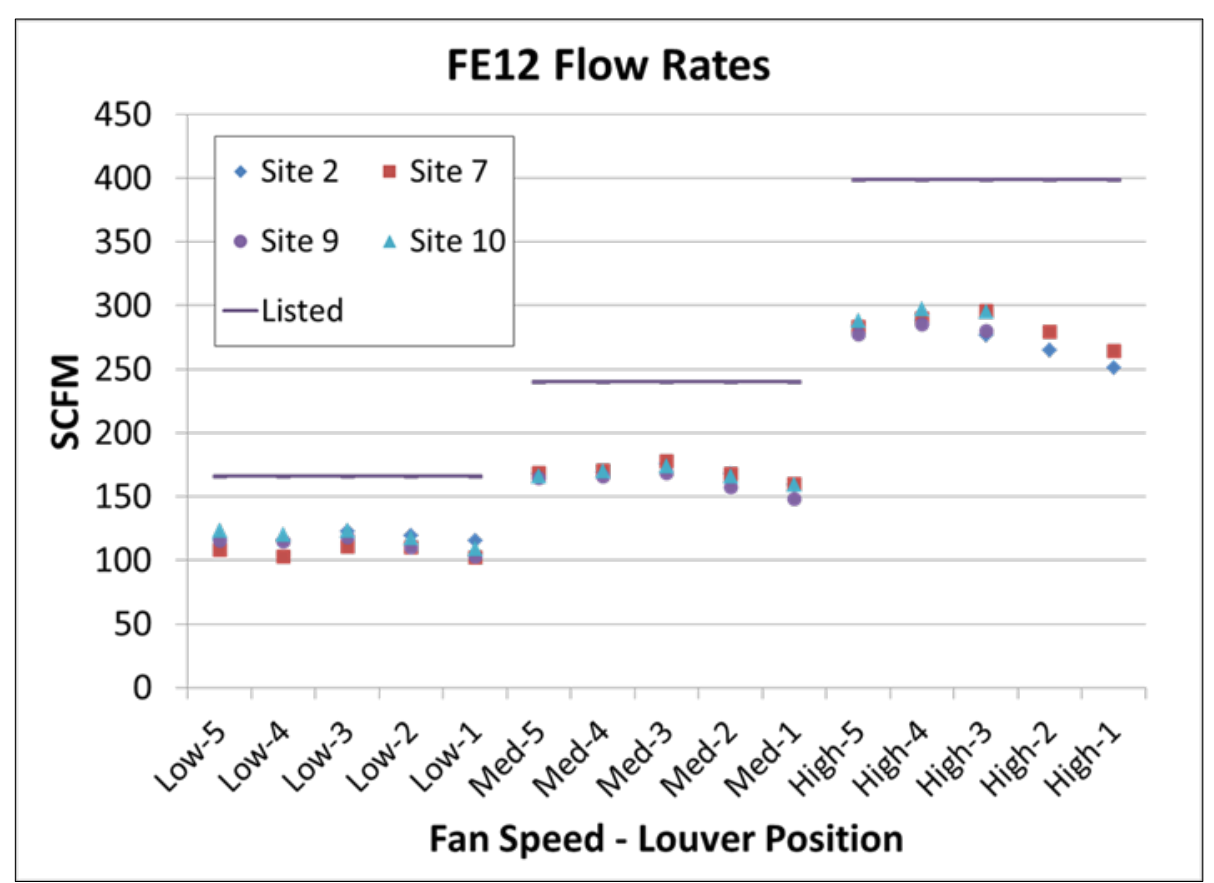

Figure 9. Measured FE12 flow rates

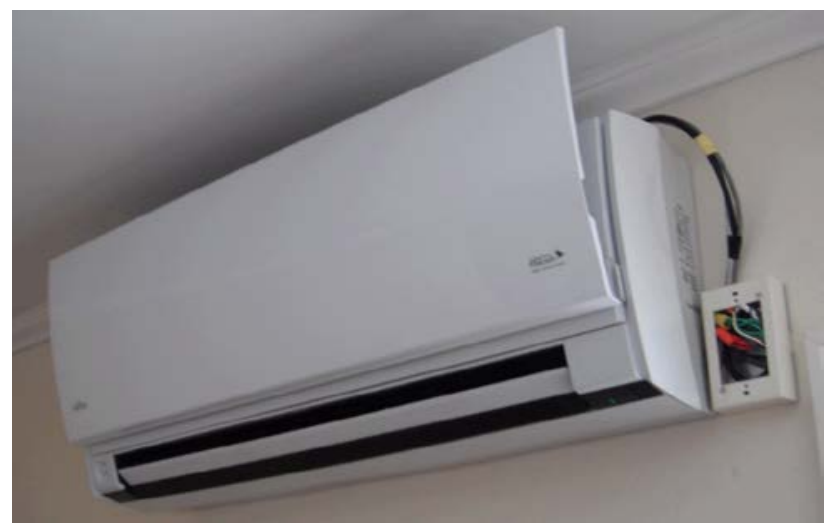

Figure 10. Fujitsu 15RLS2 indoor unit

For this unit, airflow was measured at five speeds only; flow rates at different louver positions were not measured. Unlike the Mitsubishi controller, the Fujitsu controller did not display louver position. As a result, once the rigid plenum was placed over the unit, it was difficult to assess which louver position was active. The homeowners indicated that they always left the louver in the lowest position, so CARB measured flow rates at this position. The flow rates measured are shown in Figure 11. 


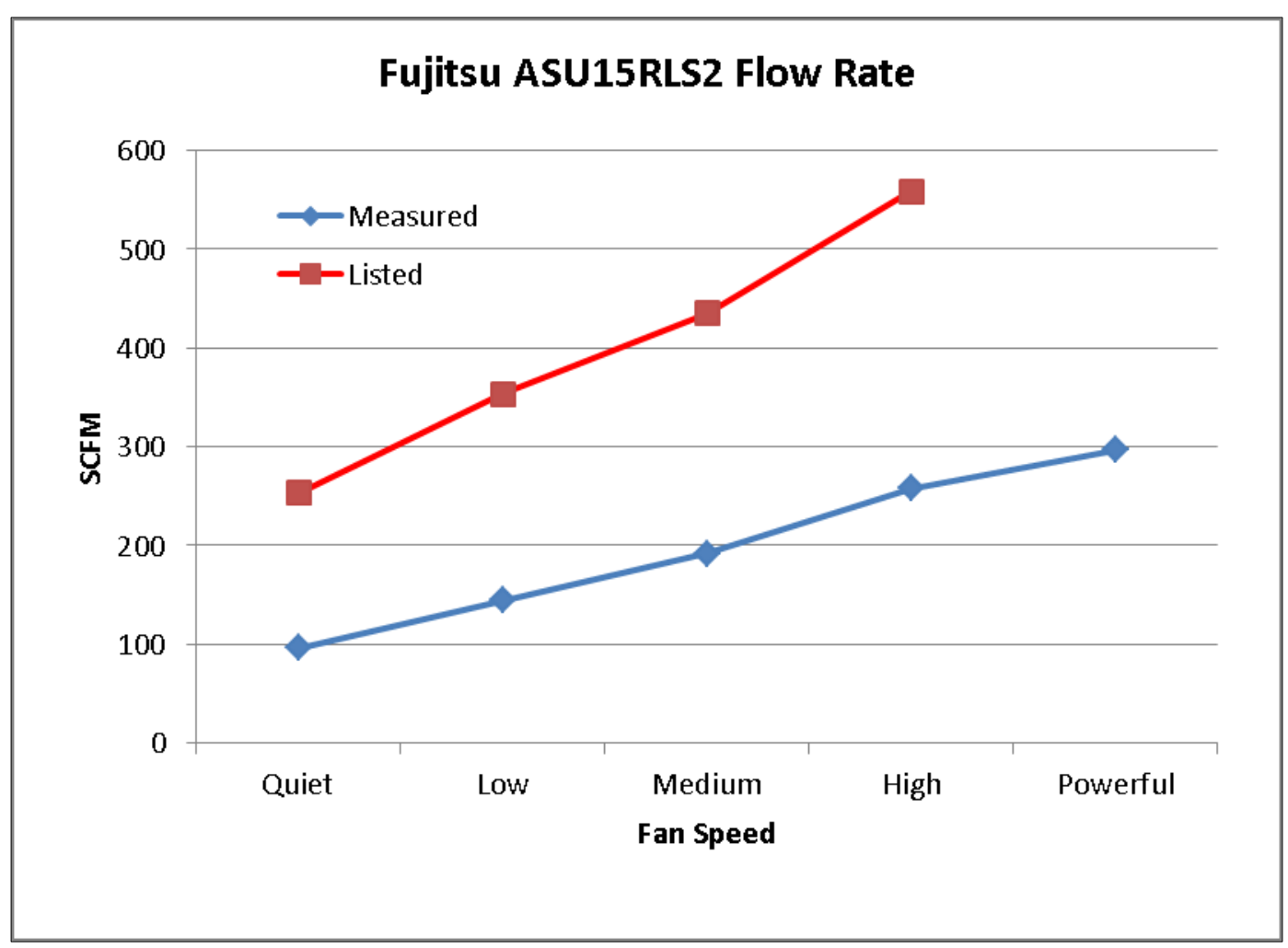

Figure 11. Fujitsu ASU15RLS flow rates

\subsection{Measured COPs}

COPs varied widely from site to site. Table 5 displays a study-wide summary of monthly COPs for each of the sites monitored and overall COP for the entire monitoring period.

Table 5. Monthly COPs

\begin{tabular}{c|c|c|c|c|c|c|c}
\hline Month & Site 1 & Site 2 & Site 4 & Site 5 & Site 8 & Site 9 & Site 10 \\
\hline Heat Pump Model & FE18 & FE12 & FE18 & 15RLS2 & FE18 & FE12 & FE12 \\
Nov 2013 & 1.3 & - & - & - & - & - & - \\
\hline Dec 2013 & 1.6 & - & 2.3 & - & - & - & - \\
\hline Jan 2014 & 1.4 & 2.0 & 2.4 & - & - & - & - \\
Feb 2014 & 1.6 & 1.9 & 2.2 & 1.8 & - & - & - \\
Mar 2014 & 1.8 & 2.0 & 2.3 & 1.7 & 2.2 & 1.0 & 1.8 \\
\hline April 2014 & 2.2 & 1.9 & 3.1 & - & 2.5 & 1.3 & 2.4 \\
Overall & 1.6 & 2.0 & 2.3 & 1.7 & 2.3 & 1.1 & 2.1 \\
\hline Total Days of Data & 204 & 141 & 142 & 28 & 44 & 57 & 51 \\
\hline
\end{tabular}

As Table 5 indicates, there were issues with collecting data at many sites. There were no useful data available from Site 3 (faulty temperature sensor), Site 6 (missing return temperature data), and Site 7 (missing current data). Site 2 was a new home; it was not occupied until January 2014. It is unclear why there was so much missing data from Sites 5-10. Efficiency Vermont installed the PowerWise monitoring systems late in 2013, but data were only available for the later part of the winter and early spring. 


\subsubsection{Coefficient of Performance versus Outdoor Air Temperature}

Figure 12 through Figure 18 illustrate daily COPs versus outdoor dry bulb (ODB) temperatures for each site. Ideally, outdoor wet bulb temperature would have been used for this comparison to account for effects that humidity has on the outdoor coils' performance. Unfortunately, the monitoring package did not provide relative humidity from the local weather station. As temperature is the primary influence of performance, the general trend can still be observed. 


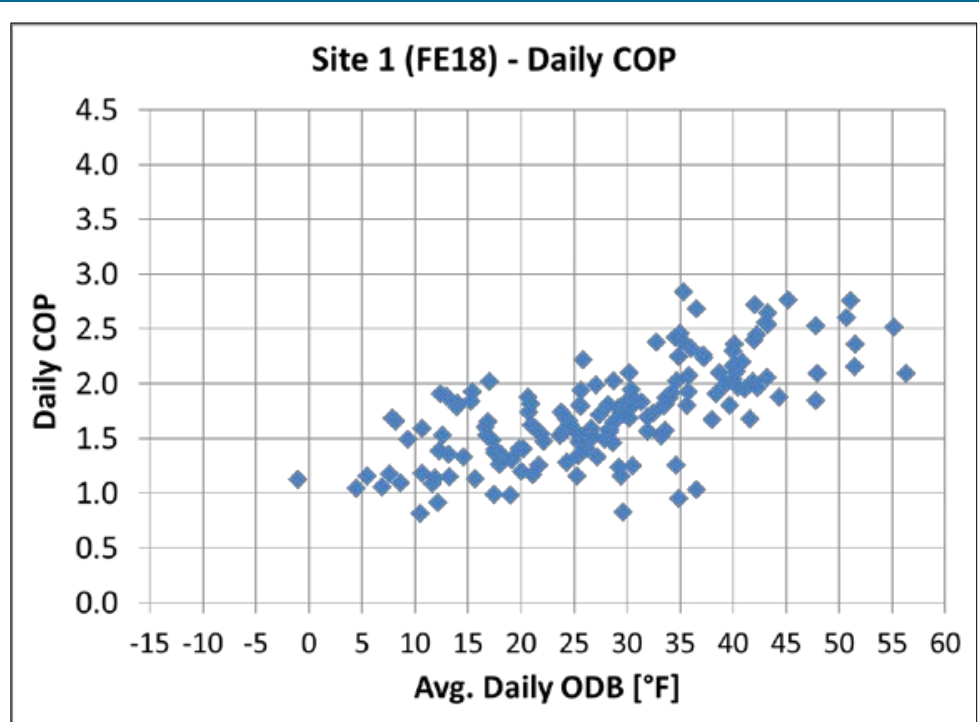

Figure 12. Site 1 daily COP versus ODB

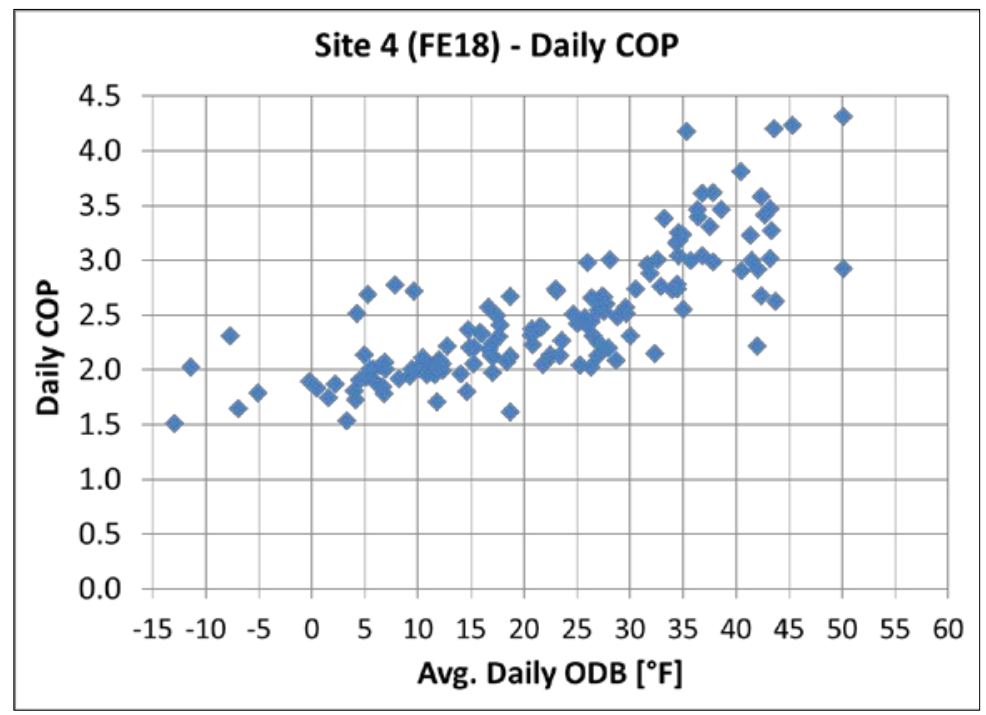

Figure 14. Site 4 daily COP versus ODB

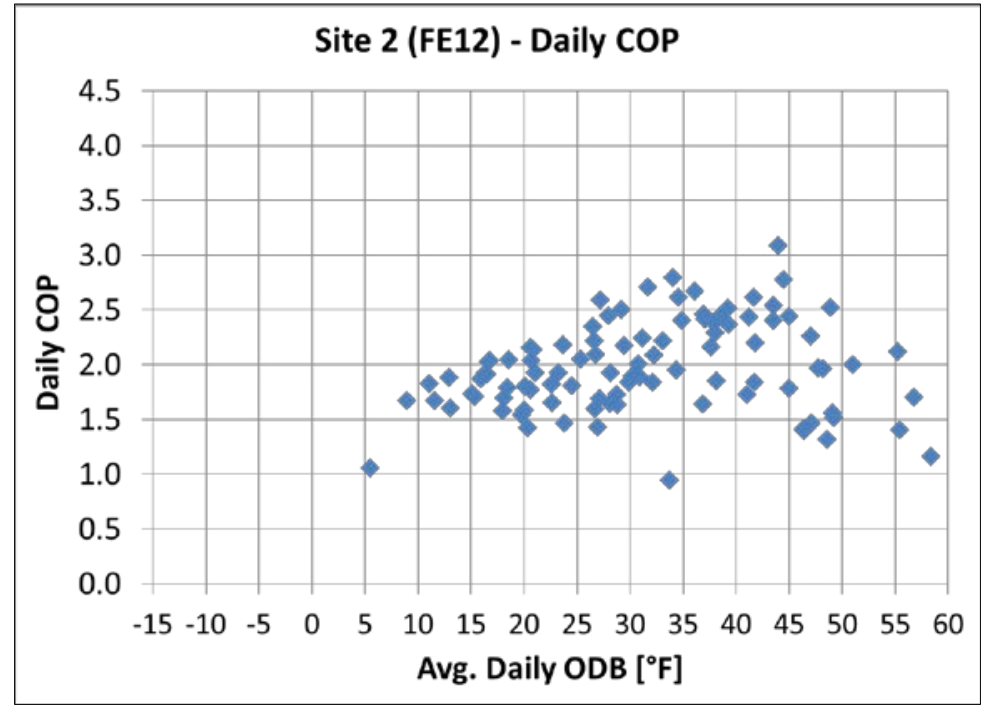

Figure 13. Site 2 daily COP versus ODB

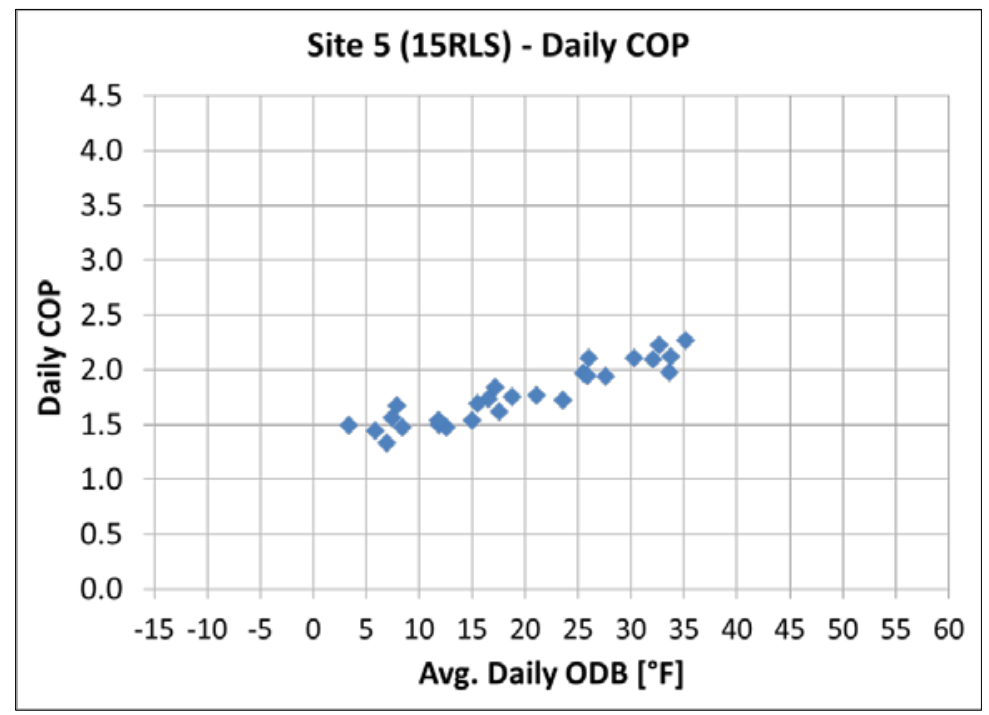

Figure 15. Site 5 daily COP versus ODB 


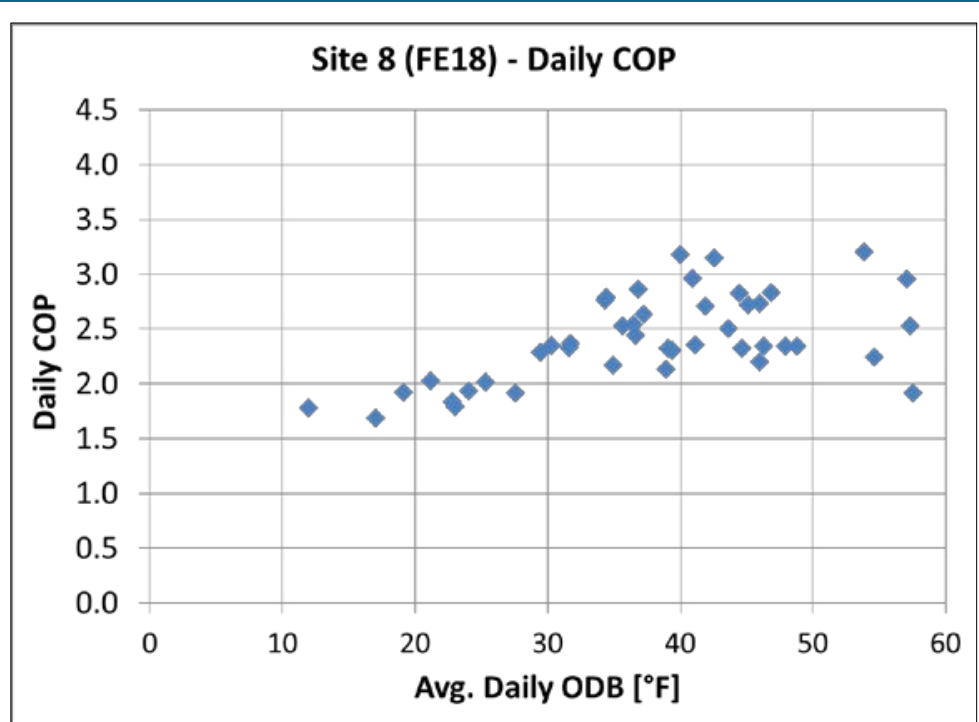

Figure 16. Site 8 daily COP versus ODB

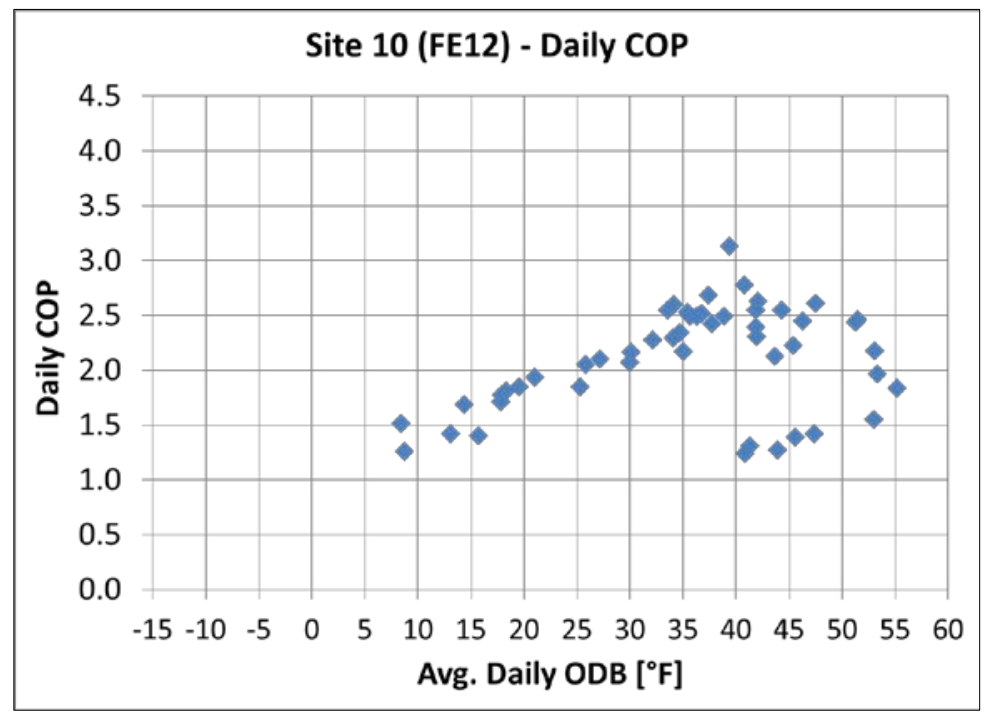

Figure 18. Site 10 daily COP versus ODB

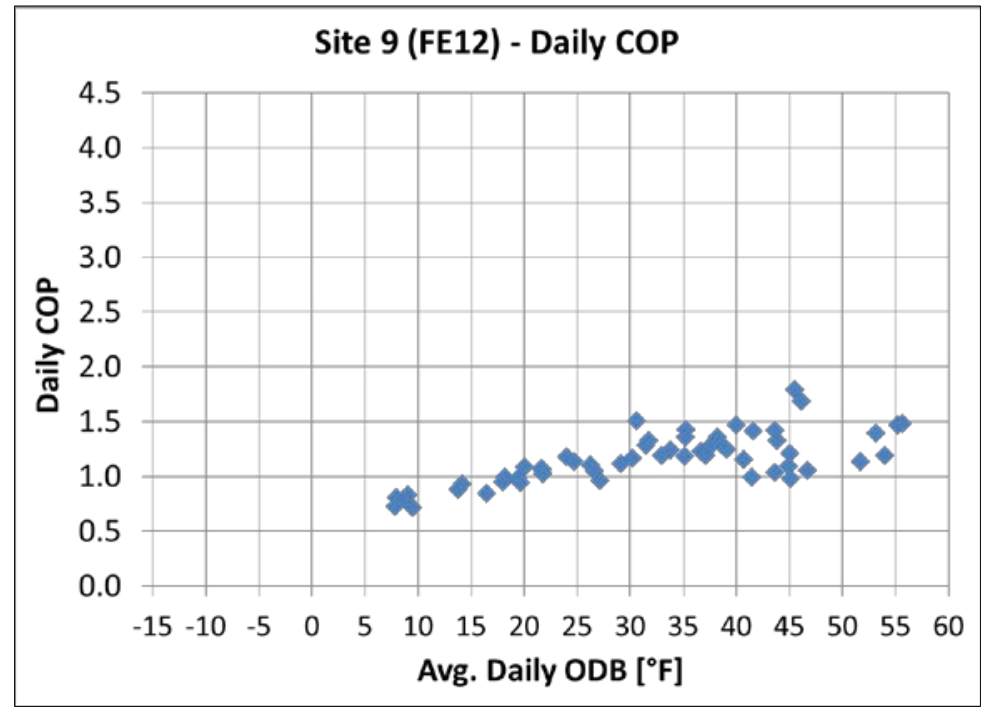

Figure 17 . Site 9 daily COP versus ODB 


\subsubsection{Heating Capacity}

For Mitsubishi heat pumps, the manufacturer listed heating capacities at two compressor speeds: intermediate and maximum. These are steady-state capacities (i.e., no cycling or defrost) and are published for an indoor dry bulb temperature of $70^{\circ} \mathrm{F}$. Comparing heat output measured in the field under varying conditions to steady-state capacity values is somewhat problematic; however, it is still an informative comparison. In Figure 19 and Figure 20, each point represents 1 hour of measured data. Heat delivered by the heat pump during each hour is plotted versus the average outdoor air temperature at that same hour. The heat pump was not necessarily operating continuously during each hour and was subject to changing thermostat set points, varying return air temperatures, defrost cycles, etc. The red line traces the maximum heat output observed at each outdoor air temperature. For reference, lines showing the published heat pump capacities at maximum and intermediate compressor speeds are shown on the same charts. Site 4 had one of the most efficient heat pumps monitored; it was the primary heating source in the home. The heat pump was seen to supply $15 \mathrm{kBtu} / \mathrm{h}$ even at $-15^{\circ} \mathrm{F}$. Below this temperature, output seems to drop sharply. This heat pump appears to match fairly well to the load as the heat pump often runs near full capacity. At temperatures above $30^{\circ} \mathrm{F}$, the load drops substantially below the maximum listed capacity.

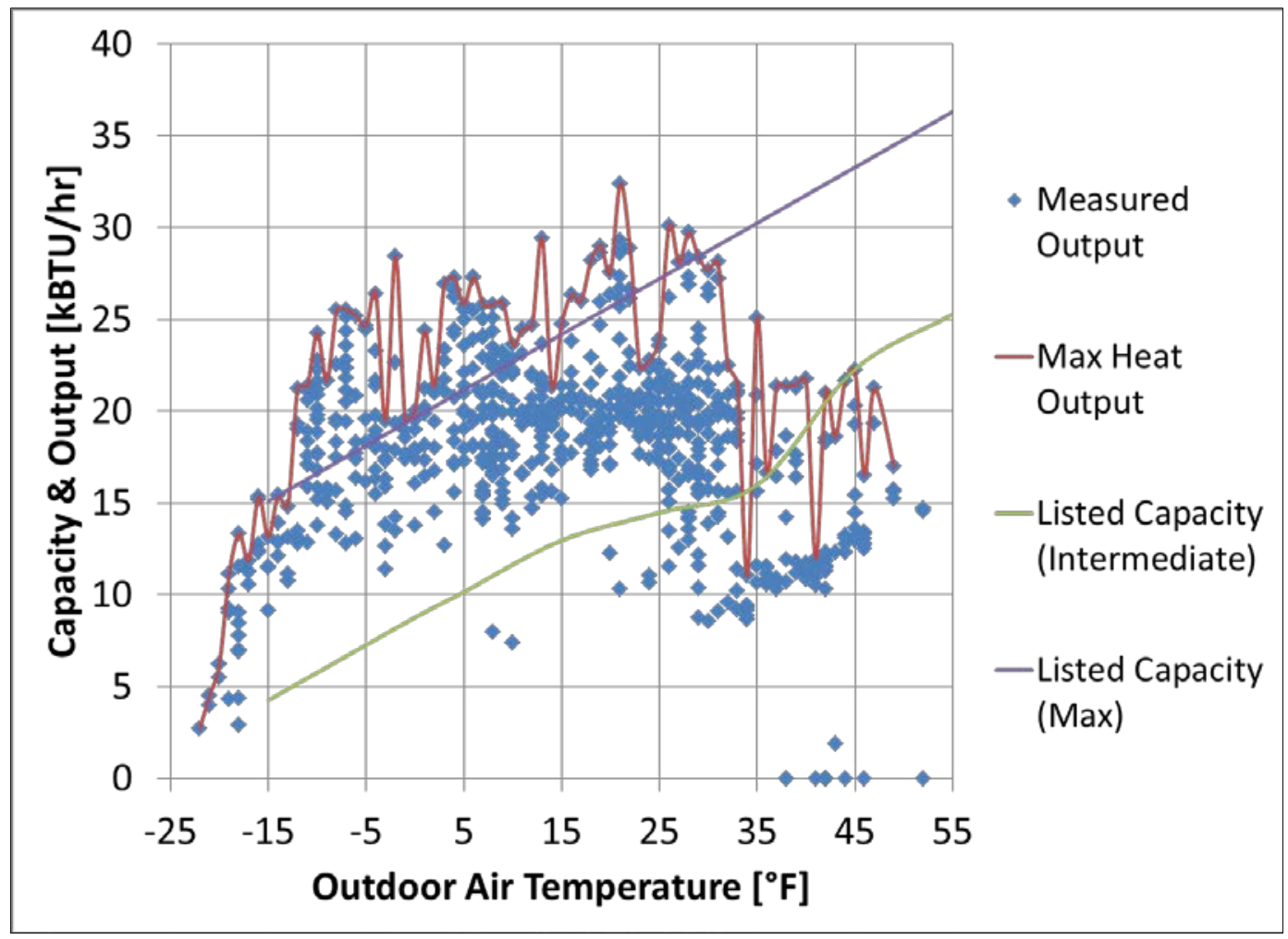

Figure 19. Hourly heat delivered versus outdoor air temperature at Site 4 during January 


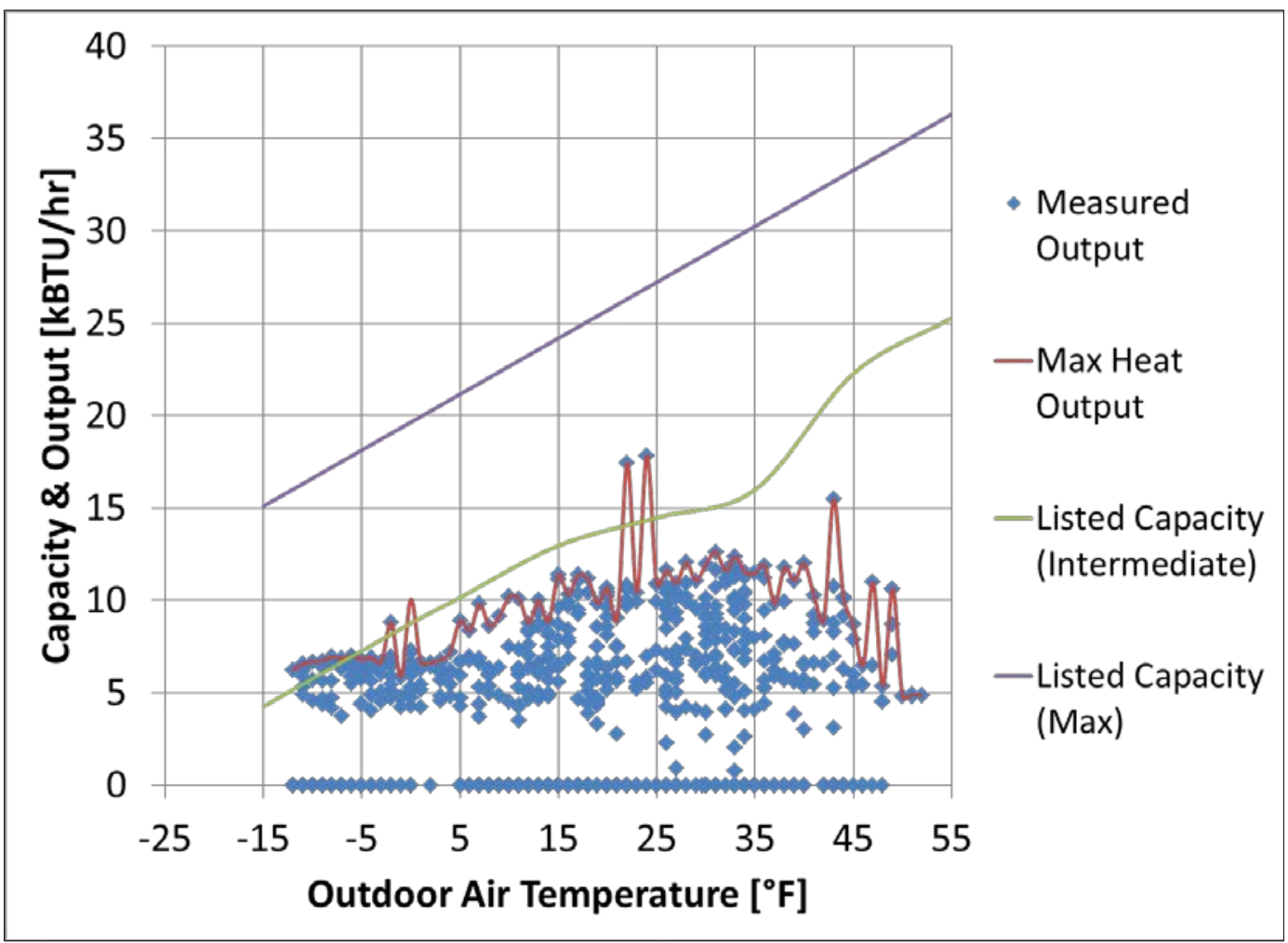

Figure 20. Hourly heat delivered versus outdoor air temperature at Site 1 during January

By contrast, the system at Site 1 had a relatively poor seasonal COP (1.6) and delivered much less heat to the home. The heat pump at this site was also a Mitsubishi FE18, but it was used as supplemental heating to a hydronic system with an oil boiler. While it is not possible to explain these differences in efficiency and capacity entirely, CARB suspects the key causes for the differences are as follows:

- Higher return air temperatures at Site 1 . At Site 4 , return air temperatures averaged $71^{\circ} \mathrm{F}$ in January. At site 1, the average return air temperature was $75^{\circ} \mathrm{F}$ in January (COP at Site 1 was especially poor in January; see Table 5).

- At Site 1, the homeowner had the fan speed set to "low" during the entire winter. Lower fan speed can obviously limit heat output, and therefore has the potential to reduce efficiency. If the compressor runs at higher speeds to meet a significant heat load but the low fan speed limits heat output, this could result in lower efficiency.

- At Site 1, the heat pump was programmed to "set back" during the day and night. This reduced electricity consumption, but during recovery (at higher compressor speeds), the heat pump was noticeably less efficient.

These issues are revisited in the Discussion section.

Figure 21 displays heat output seen during the month of February at Site 2 (FE12). At first glance, it may appear that this heat pump is underperforming, but this home was built to Passive House standards and used the heat pump as the only heat source. The home's design heating load was calculated at approximately $6,000 \mathrm{Btu} / \mathrm{h}$, and comfortable indoor conditions were 
maintained all winter. The low output, therefore, seems to be a result of very low loads rather than of the heat pump not meeting listed capacities.

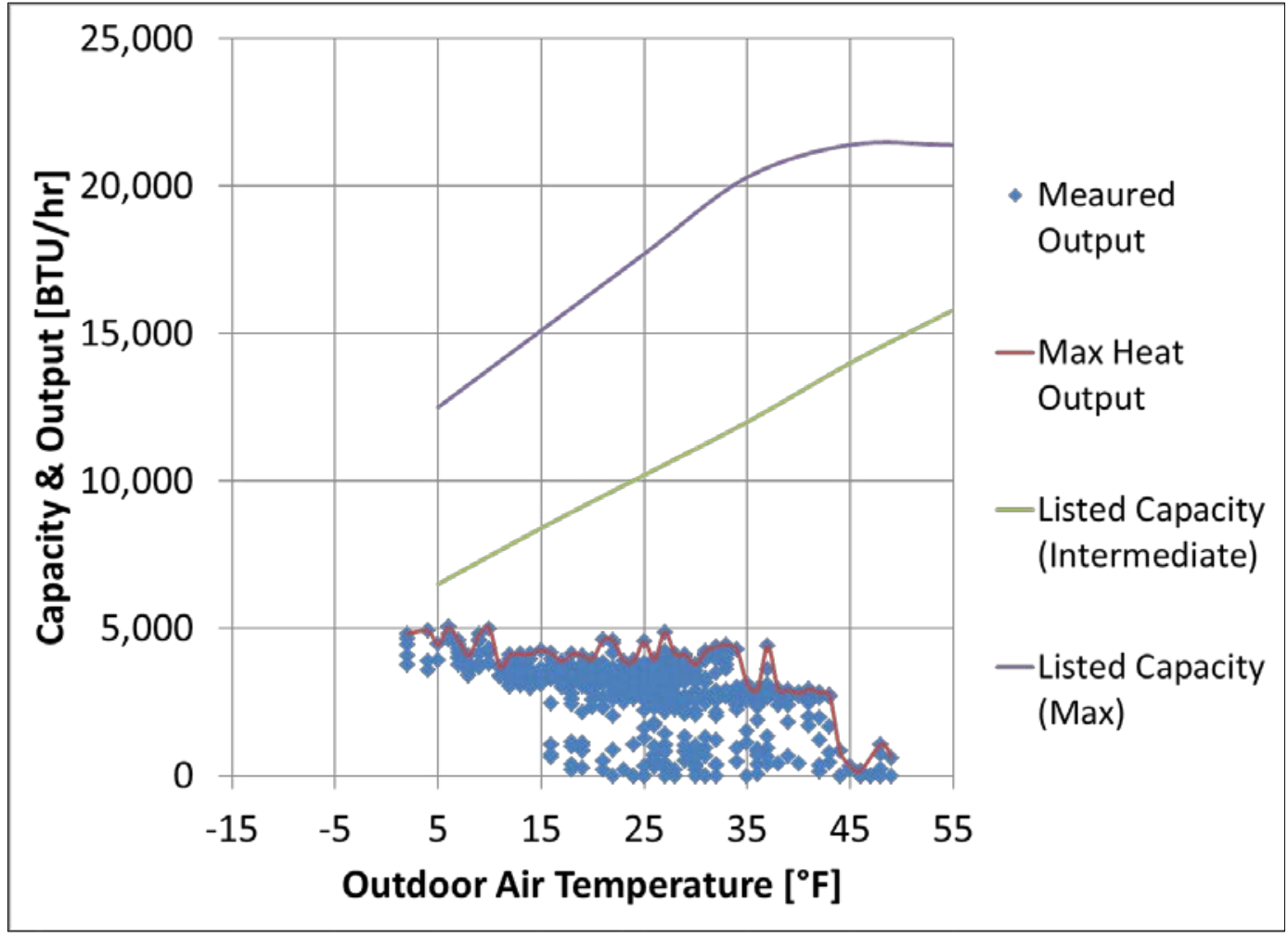

Figure 21. Hourly heat delivered versus outdoor air temperature at Site 2 during February

The heat outputs for the other sites are shown in Figure 22 through Figure 25. Site 9 used a Mitsubishi FE12 for supplemental heating. It had the lowest overall COP of all sites monitored. As with Site 1, the homeowner only ran the unit in "low" fan speed. During March, outdoor temperatures still dipped down to $-10^{\circ} \mathrm{F}$; however, heat output of the system does not exceed $6 \mathrm{kBtu} / \mathrm{h}$. CARB believes that part of the low capacity and poor performance is attributed to restrictions imposed by the "low" fan speed setting. 


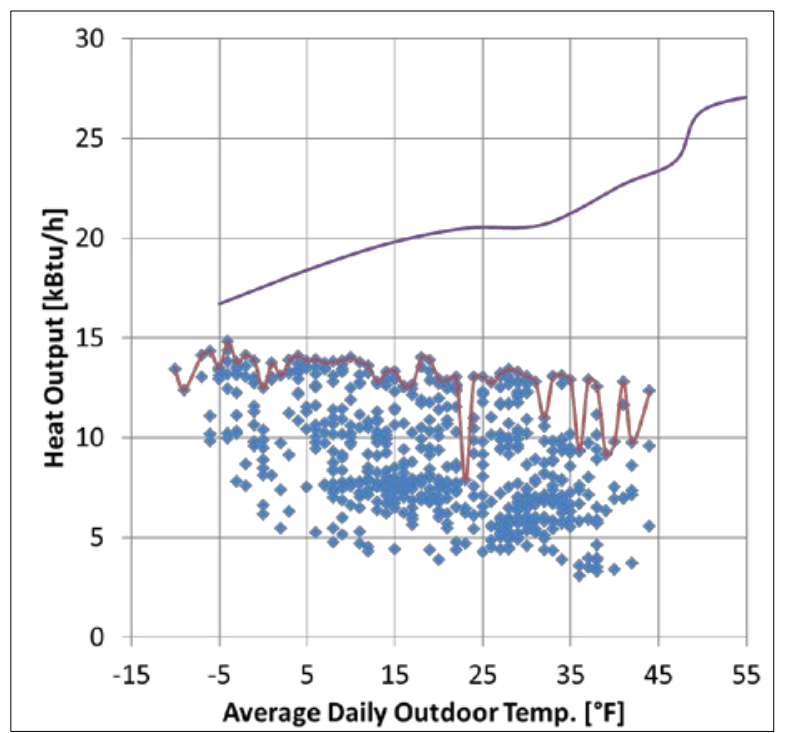

Figure 22. Heat output for Site 5 (Fujitsu 15RLS2)

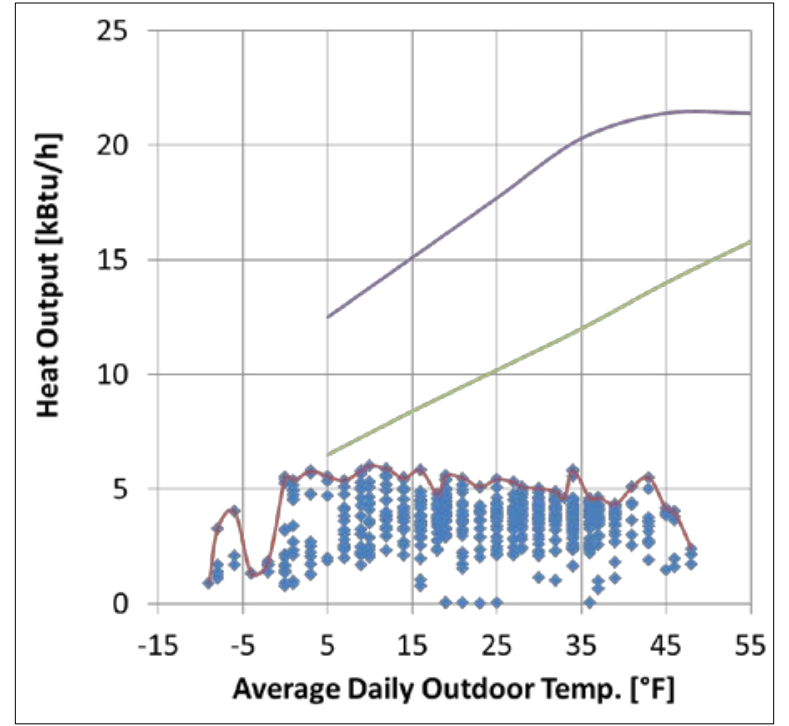

Figure 24. Heat output for Site 9 (Mitsubishi FE12)

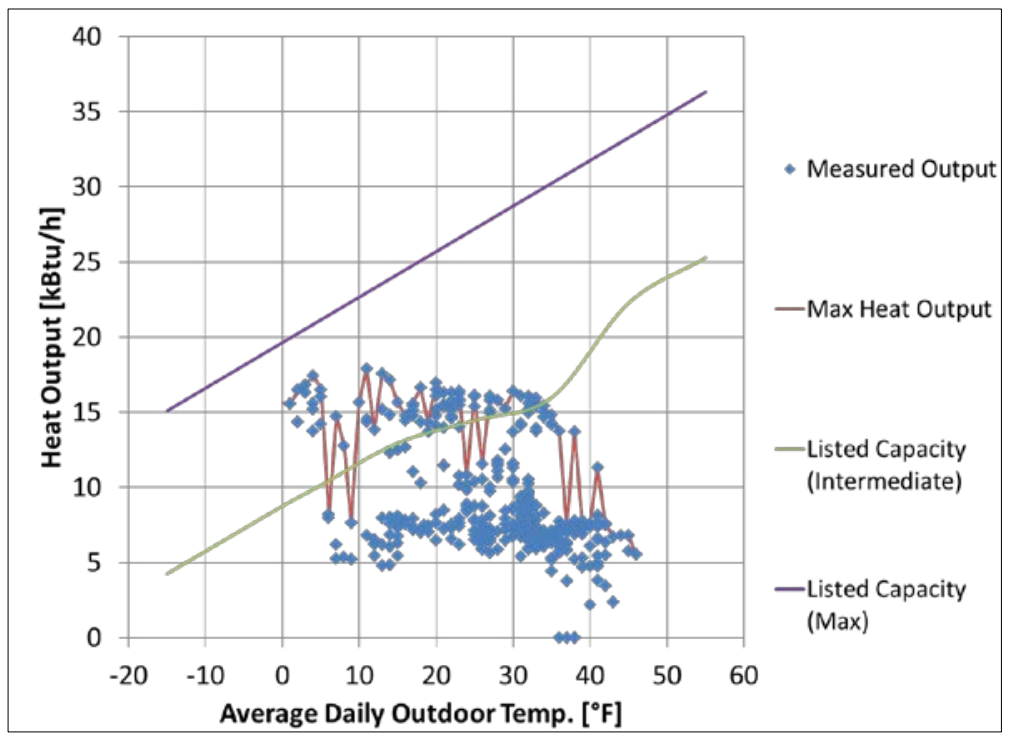

Figure 23. Heat output for Site 8 (Mitsubishi FE18)

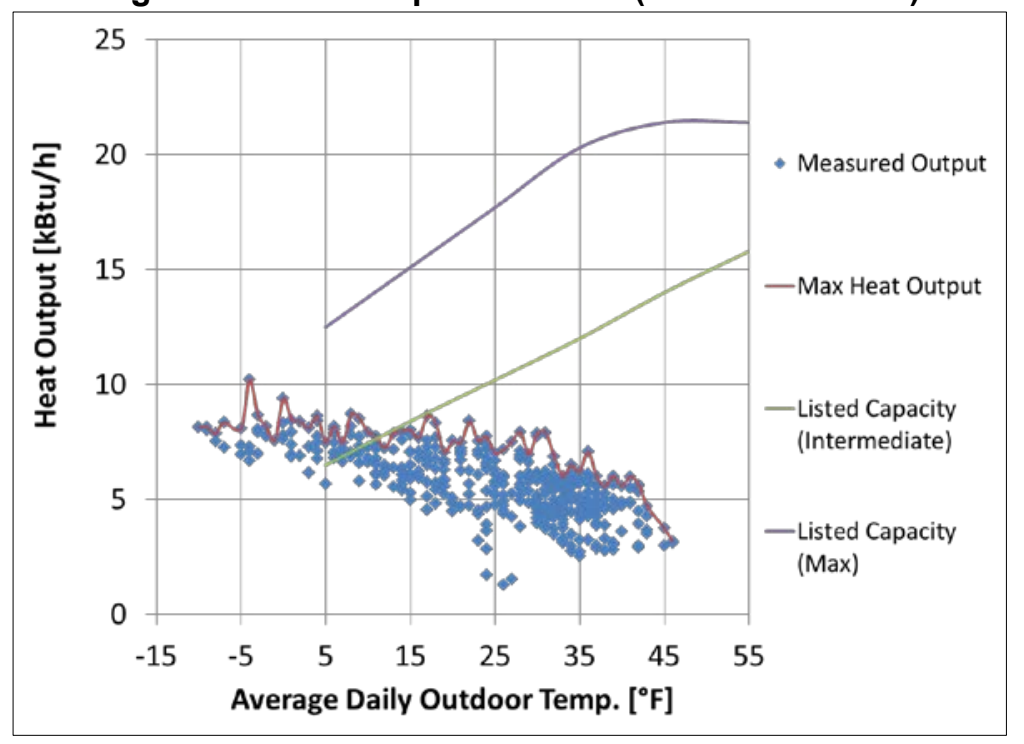

Figure 25. Heat output for Site 10 (Mitsubishi FE12) 


\subsubsection{Defrost}

A data processing algorithm was developed to mine heat pump data for periods where the unit was operating in defrost mode. The team investigated several defrost identifiers before arriving at the chosen algorithm. The identifiers that were investigated included: drops in COP (high energy use with low heat output), ultra-low fan speed mode, changes in supply temperature, patterns in power use, and combinations of all of these. The method that produced the most consistent and accurate results involved searching data arrays for the following:

- Periods of steady operation (power consumption of at least 100 Watts [W] for $15 \mathrm{~min}$; $100 \mathrm{~W}$ is well above standby power and indicates the compressor is operating)

- Followed by a drop of at least $300 \mathrm{~W}$ over 1 minute (heating mode stops and the compressor turns off)

- Followed by a power increase of at least $300 \mathrm{~W}$ (compressor turns on in reverse cycle)

- Followed by a drop of at least $300 \mathrm{~W}$ within 10 minutes (compressor stops; defrost mode ends)

- Followed by an increase of at least $300 \mathrm{~W}$ (heating mode begins again) without a significant drop in the next 5 minutes.

A time period at Site 4 with an average outdoor temperature of $-9^{\circ} \mathrm{F}$ is shown in Figure 26. During this 2.5-hour period, the unit enters defrost on three occasions. Supply temperatures dip down to about $80^{\circ} \mathrm{F}$ at the end of the defrost cycle. Figure 27 through Figure 33 show minutes in defrost (for each day) as a function of average outdoor temperature for each site.

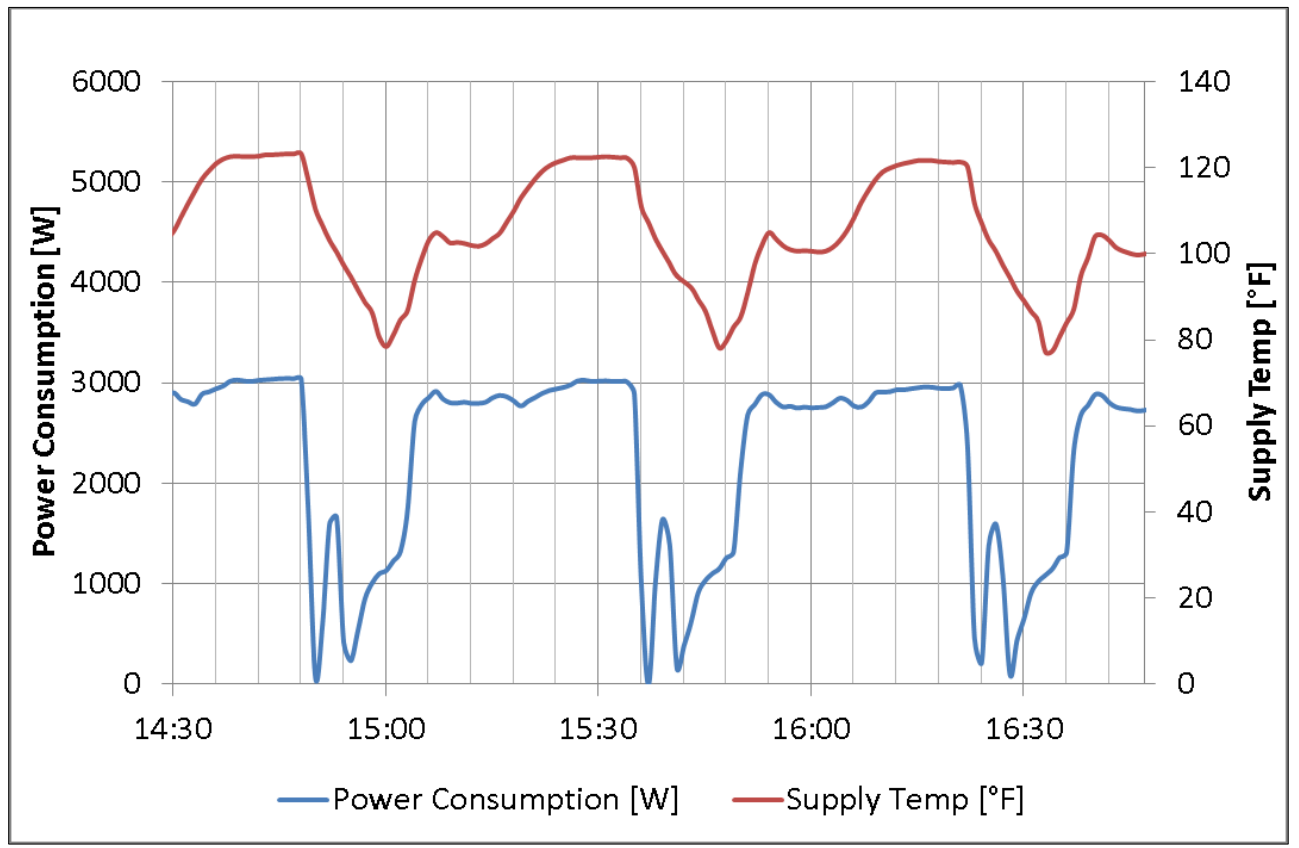

Figure 26. Examples of defrost cycles at Site 4 


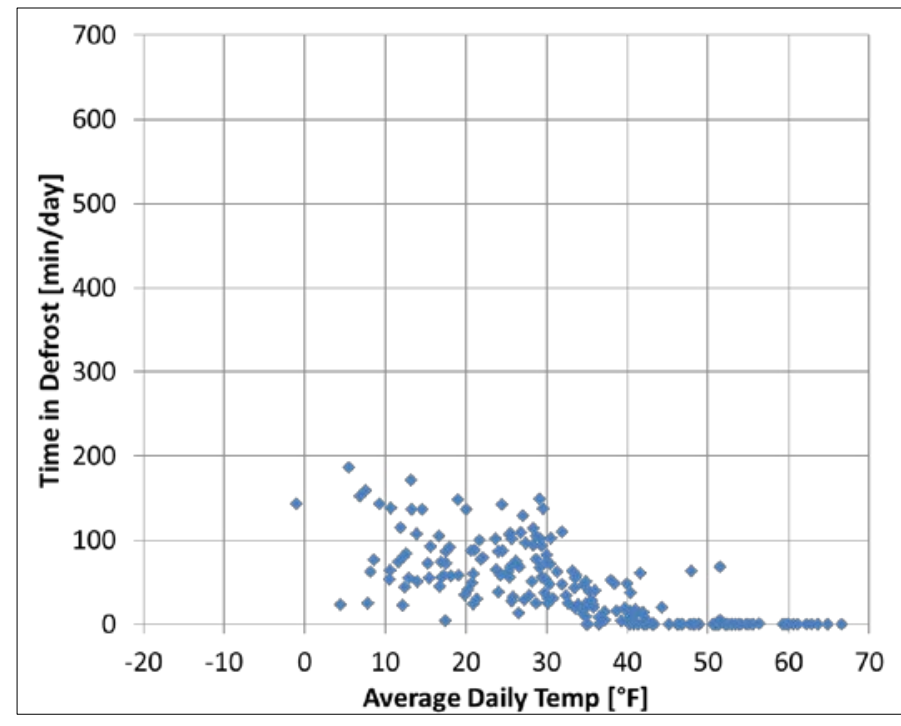

Figure 27. Site 1 defrost summary

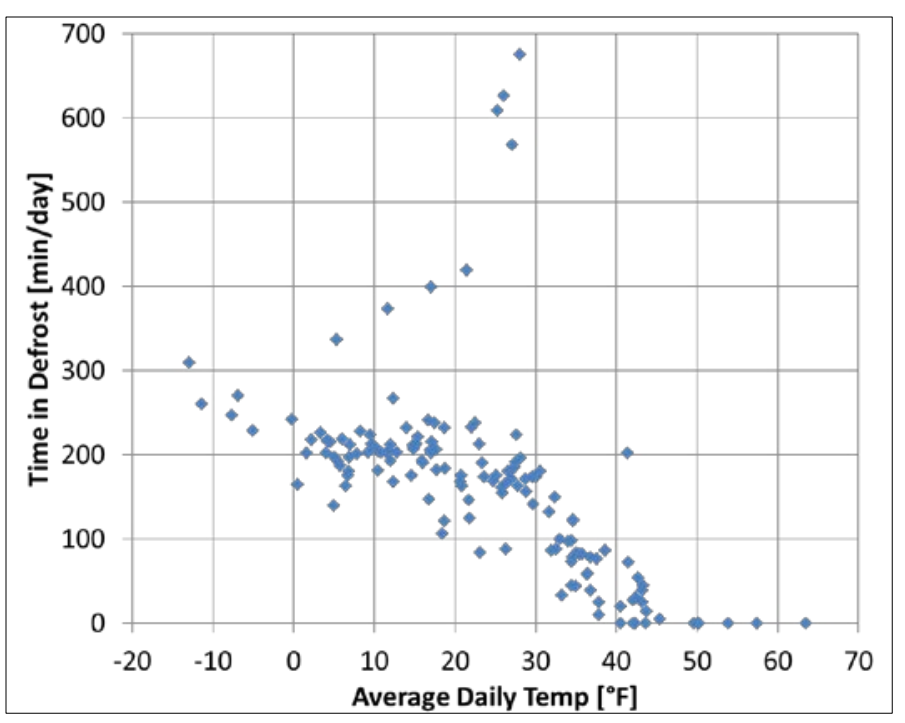

Figure 29. Site 4 defrost summary

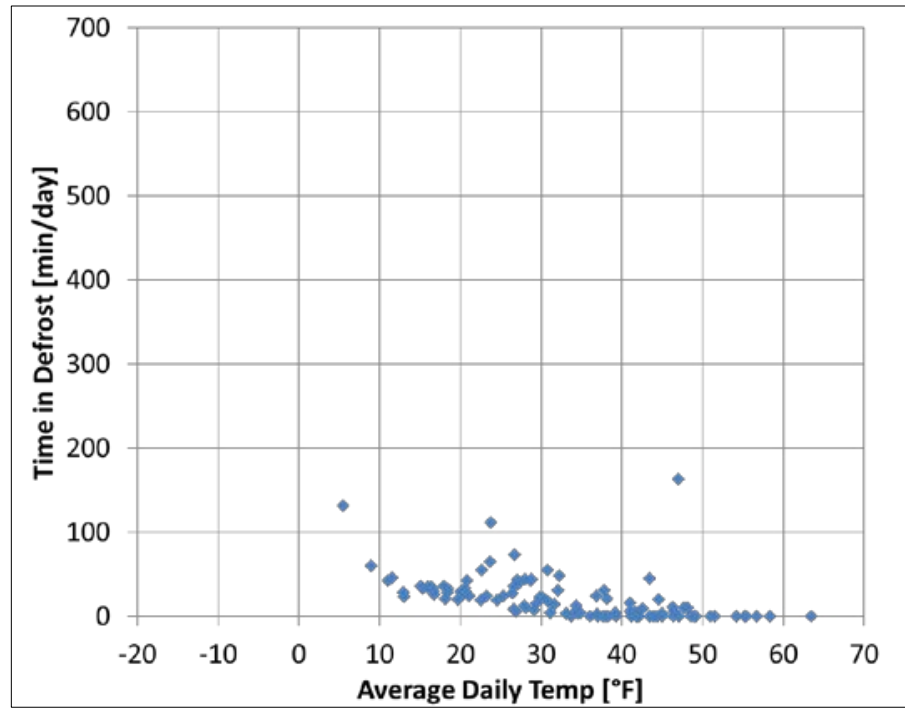

Figure 28. Site 2 defrost summary

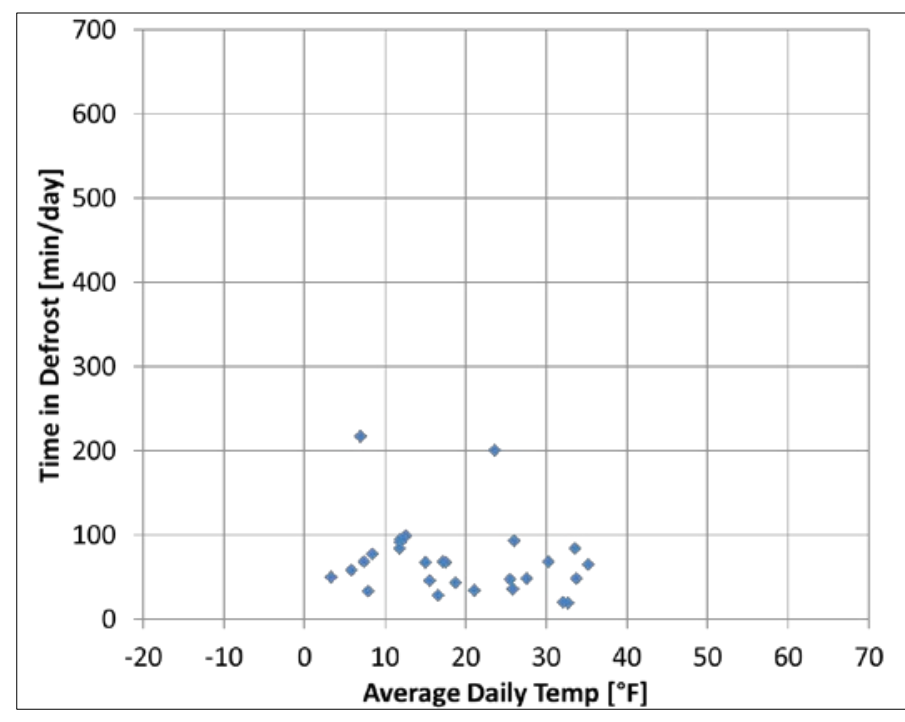

Figure 30. Site 5 defrost summary 


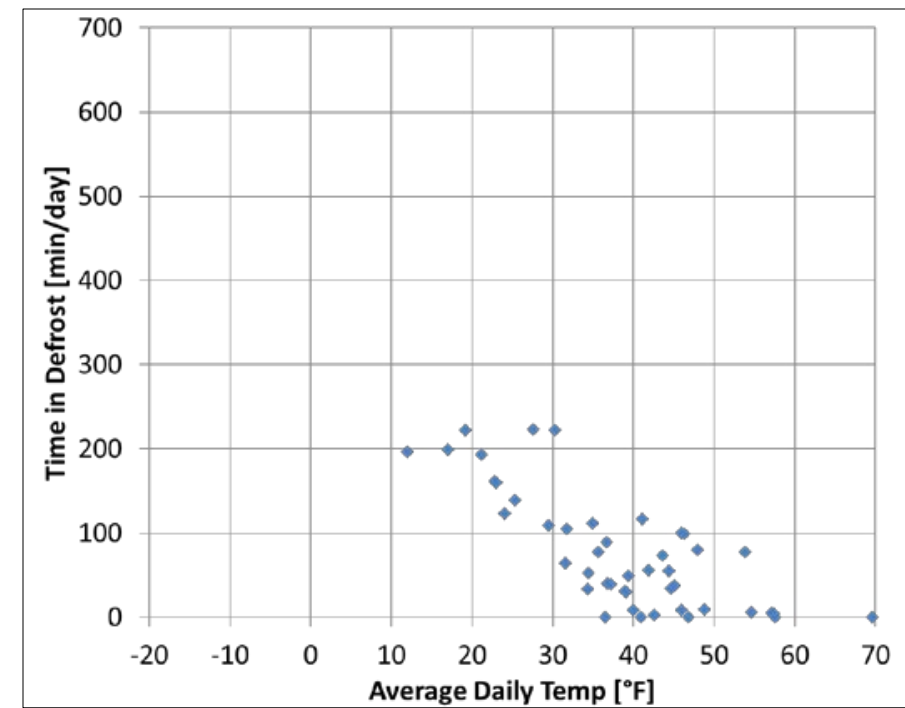

Figure 31. Site 8 defrost summary

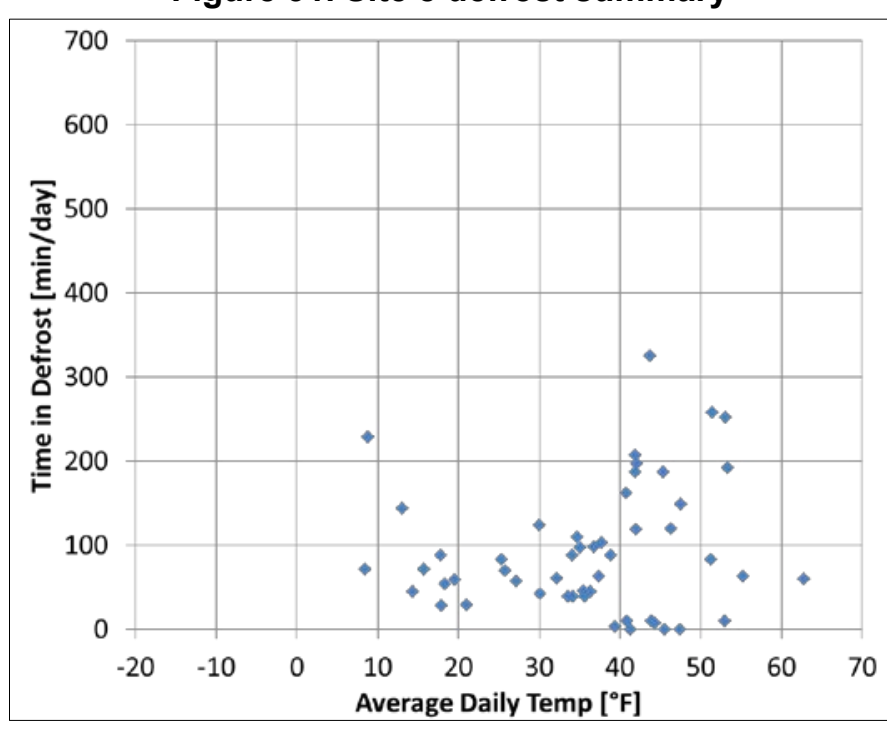

Figure 33. Site 10 defrost summary

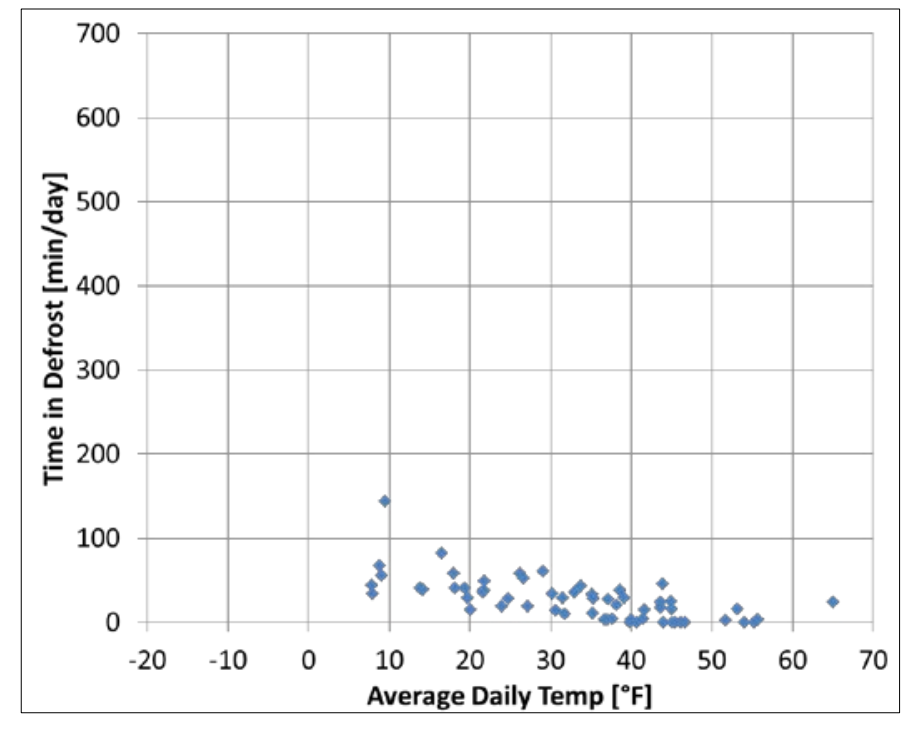

Figure 32. Site 9 defrost summary 


\subsubsection{Homeowner Feedback}

At the time of flow testing, CARB spoke with each of the homeowners to gauge comfort and overall satisfaction with the heat pump. Responses were generally very positive, but comments from homeowners (in Table 6) provided some insights into how the units were operated.

Table 6. Homeowner Comments

\begin{tabular}{|c|c|c|}
\hline Site & $\begin{array}{l}\text { DHP Heating } \\
\text { Role }\end{array}$ & Comments \\
\hline 1 & Supplemental & $\begin{array}{l}\text { Manually turns off during very cold weather. Sets back temperature during } \\
\text { day (at work) and night (sleeping). During mild weather, is able to heat home } \\
\text { for less than } \$ 1 / \text { day (unclear if this includes fuel oil). }\end{array}$ \\
\hline 2 & Primary & $\begin{array}{l}\text { Leaves on auto. Satisfied that DHP is able to heat entire home. As fan coil is } \\
\text { mounted rather high, the temperature is set rather high }\left(72^{\circ}-74^{\circ} \mathrm{F} \text { to keep }\right. \\
\text { temperature at } 4 \mathrm{ft} \text { above floor at } 68^{\circ} \mathrm{F}-70^{\circ} \mathrm{F} \text {. }\end{array}$ \\
\hline 3 & Supplemental & Installed remote thermostat to prevent short cycling. \\
\hline 4 & Primary & $\begin{array}{l}\text { The unit is located in the basement. Occupants leave the vanes pointed up } \\
\text { during winter. }\end{array}$ \\
\hline 5 & Supplemental & Saw a noticeable decrease in propane use after DHP was installed. \\
\hline 6 & Supplemental & Pleased with the system. \\
\hline 7 & Supplemental & $\begin{array}{l}\text { Homeowner shut DHP off in late November; he didn't think it would work } \\
\text { well during cold weather. }\end{array}$ \\
\hline 8 & Supplemental & $\begin{array}{l}\text { Very pleased with the system. The unit was mounted over the couch in living } \\
\text { room. When the unit defrosted, it would dump uncomfortably cold air on } \\
\text { people sitting on couch. }\end{array}$ \\
\hline 9 & Supplemental & $\begin{array}{l}\text { Home is a second home used during weekdays. Owner uses the DHP but is not } \\
\text { satisfied with the controls. }\end{array}$ \\
\hline 10 & Supplemental & $\begin{array}{l}\text { Initially, the system was not working, but overall they are happy with the } \\
\text { system. }\end{array}$ \\
\hline
\end{tabular}




\section{Discussion}

\subsection{Indoor Airflow Rates}

Measuring airflow without influencing the flow itself is a difficult task to carry out in the field. While based on sound principles and precedent, CARB's test method underwent numerous iterations before the process was finalized. CARB focused intently on the flow measurement technique because measured flow rates were only $50 \%-80 \%$ of manufacturers' published rates. Laboratory studies have found much closer agreement for the same models tested (Winkler 2011), so CARB engineers were concerned that these field results were not accurate.

After many conversations with industry professionals and evaluating several different test methods, CARB believes the test results are indeed accurate. However, in the future, CARB would like to validate this method against more rigorous laboratory tests. With interest from a local fan manufacturer and a local ASHP representative, CARB began working to schedule this laboratory validation. Unfortunately, because of time and budget constraints, this effort stalled. CARB hopes to further pursue this lab verification test in order to strengthen validity of a flow measurement method that is suitable for use in DHP air-side energy calculations.

One airflow finding is irrefutable: the position of the adjustable louvers dramatically affects the airflow rate. Even under normal operating conditions (i.e., without the flow hood attached), CARB measured dramatic changes in return static pressure with different louver positions. Generally speaking, when louvers were in the furthest position downward, flows were lowest (near $50 \%$ of listed flow rates). The highest flow rates (near $80 \%$ of listed rates) were generally observed when louvers were pointed slightly below the horizontal. Fortunately, CARB was able to capture these flow changes by measuring changes in fan coil current. Dirty filters may reduce airflow rate in a similar manner. Figure 34 shows the filters at Site 4 when CARB performed flow testing (one half before cleaning, one half after).

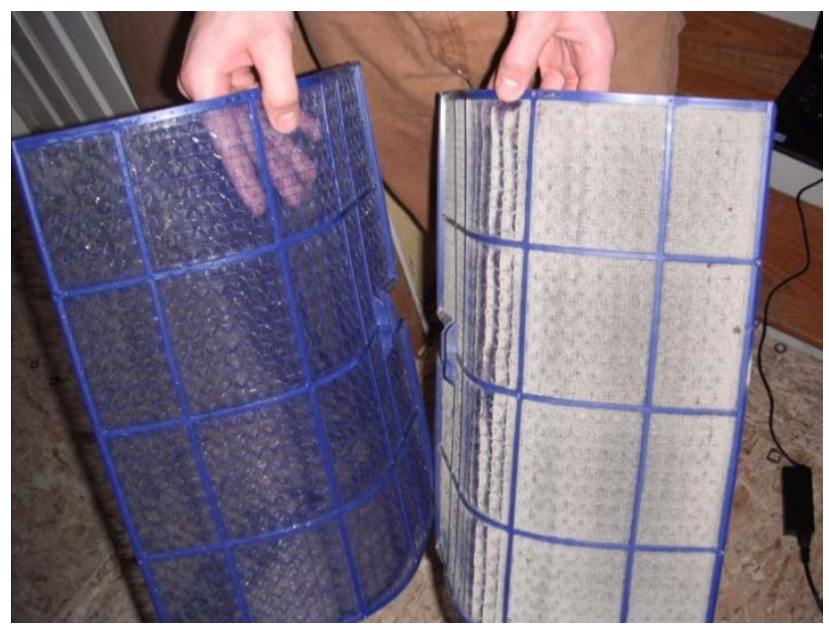

Figure 34. Filters at Site 4-one before cleaning, one after cleaning

One concerning implication of these airflow findings is that there are some other evaluation efforts that assume that flow rates provided in manufacturer literature are valid in the field. It is certainly much simpler to monitor return temperature, supply temperature, and total power only. Monitoring flow rate certainly adds time and complexity to the monitoring effort, but CARB 
believes it is critical to accurately assess heat delivered by the system. Assuming literature flow rates are delivered in the field can lead to overestimating heat pump efficiencies.

\subsection{Heat Pump Performance Criteria}

The wide range in seasonal COPs is hard to explain with certainty, but the data highlight several factors that contribute to the variations.

\subsubsection{Indoor Return Air Temperature}

As return air temperature increases, heating capacity and efficiency of heat pumps decrease. This is clearly shown in manufacturer data; Figure 35 shows an example of this for a Mitsubishi FE18 heat pump (other manufacturers show very similar trends). In the systems monitored by CARB, average return air dry bulbs averaged slightly above $75^{\circ} \mathrm{F}$ (see Table 7). Return air temperatures above $80^{\circ} \mathrm{F}$ were not uncommon.

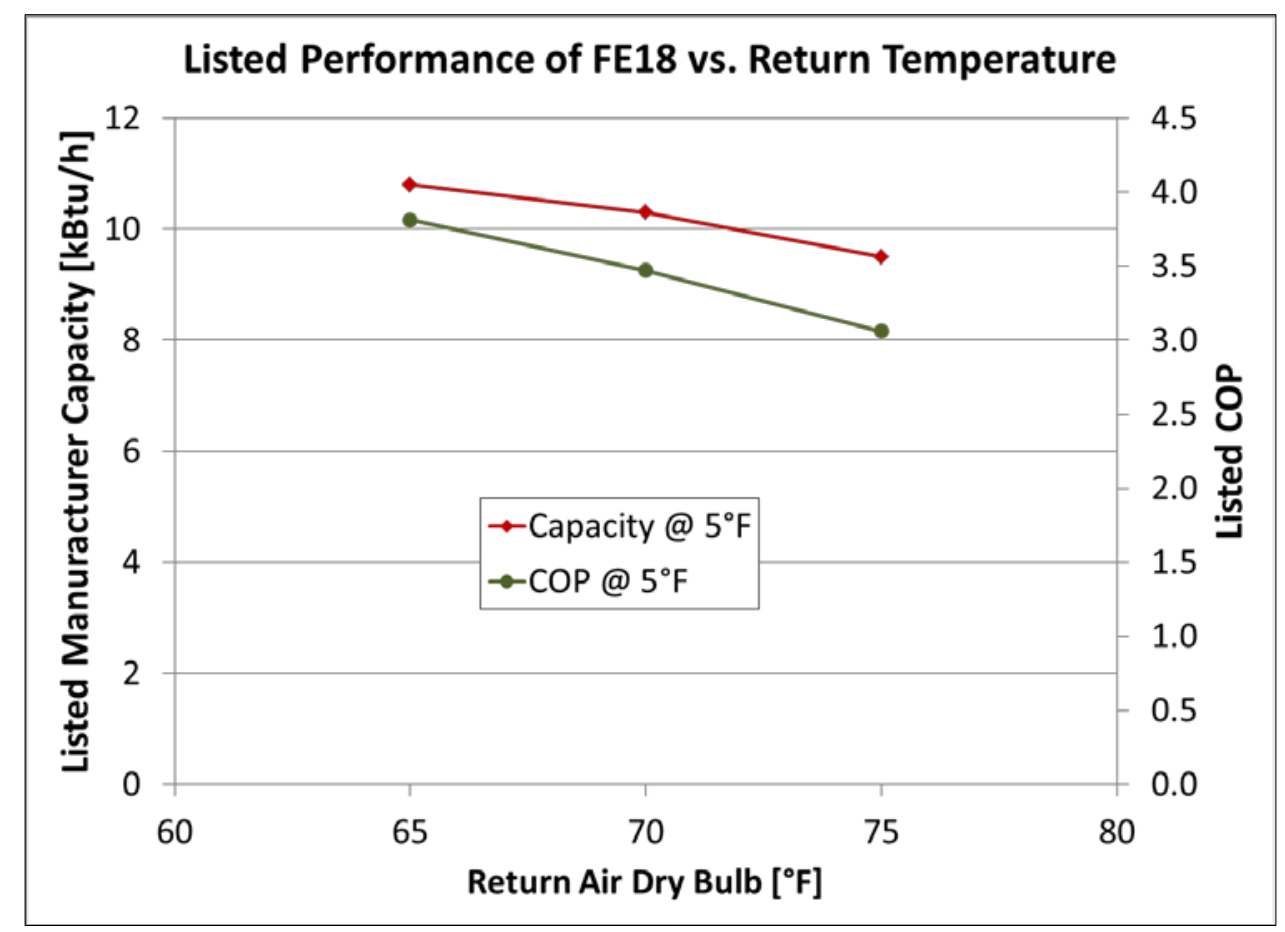

Figure 35. Manufacturer data show capacity and efficiency decrease as return air temperatures rise. These data are for intermediate or "rated" speeds at ODB of $5^{\circ} \mathrm{F}$

Table 7. Average Return Air Dry Bulb Temperatures ( $\left.{ }^{\circ} \mathrm{F}\right)$ When ASHPs Were Operating

\begin{tabular}{c|c|c|c|c|c|c|c}
\hline Month & Site 1 & Site 2 & Site 4 & Site 5 & Site 8 & Site 9 & Site 10 \\
\hline Nov 2013 & 72.1 & - & - & - & - & - & - \\
\hline Dec 2013 & 72.6 & - & 73.7 & - & - & - & - \\
\hline Jan 2014 & 74.9 & 76.0 & 71.4 & - & - & - & - \\
\hline Feb 2014 & 75.0 & 75.1 & 74.3 & 73.7 & - & - & - \\
\hline Mar 2014 & 74.8 & 75.4 & 74.3 & 74.6 & 78.8 & 75.2 & 76.6 \\
\hline Apr 2014 & 76.7 & 74.0 & 75.2 & - & 78.9 & 77.7 & 74.7 \\
\hline
\end{tabular}


Most of the heat pumps were mounted high up on walls (see Site 2 fan coil in Figure 36). Air temperatures near the ceiling will certainly be warmer than at other heights. To examine the potential of hot supply air short circuiting back to the return, CARB performed some simple tests with an infrared camera at two sites. Figure 37 shows that while direct short-circuiting does not appear to be occurring, there is potential for return temperatures to be higher when the heat pump is operating. While air temperatures elsewhere in the homes were not monitored, the room air temperatures during testing were in the $68^{\circ}-70^{\circ} \mathrm{F}$ range - significantly lower than the typical return air temperatures measured.

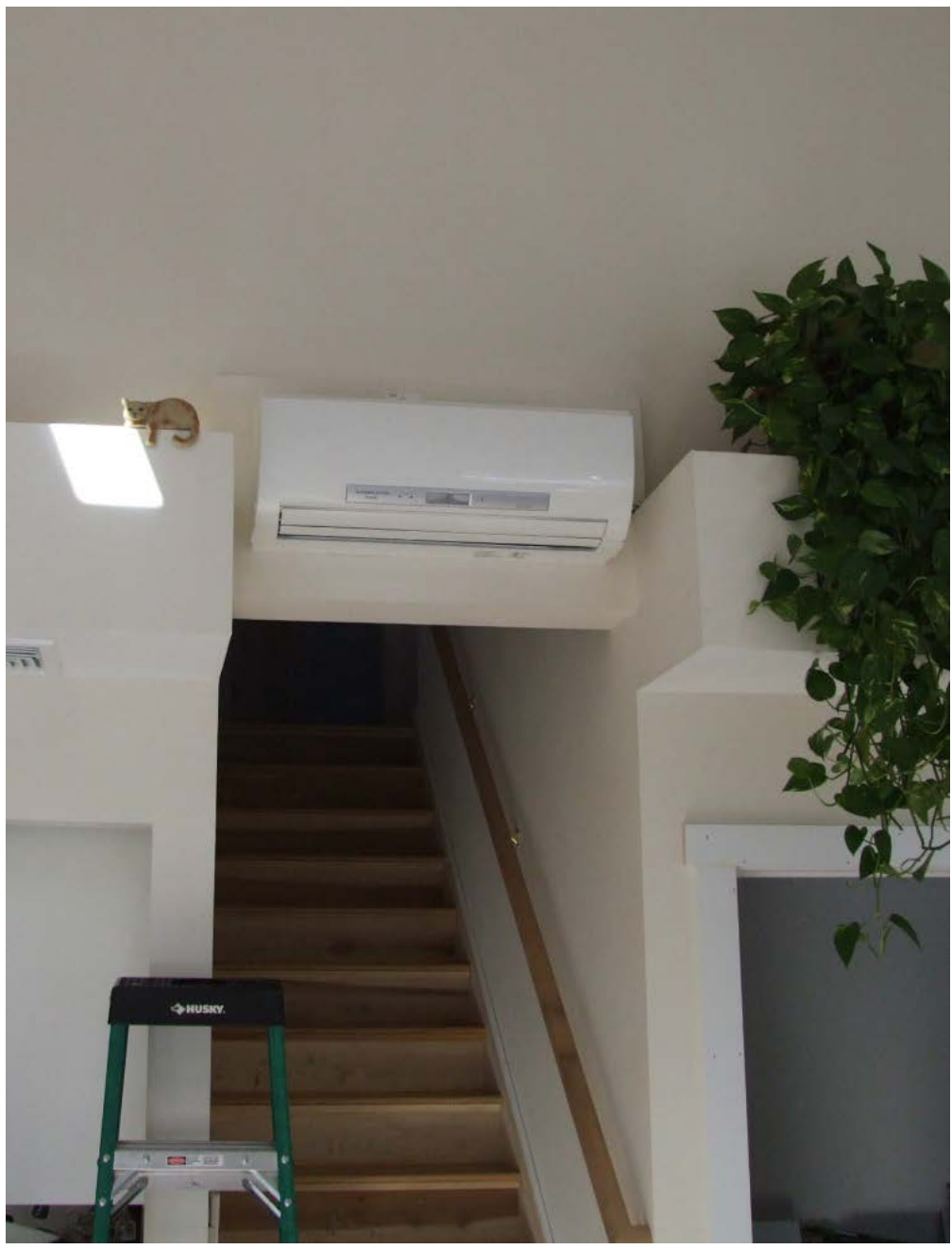

Figure 36. The heat pump at Site 2 was located above a stairway in an area with a vaulted ceiling. This location may have led to relatively high return air temperatures 


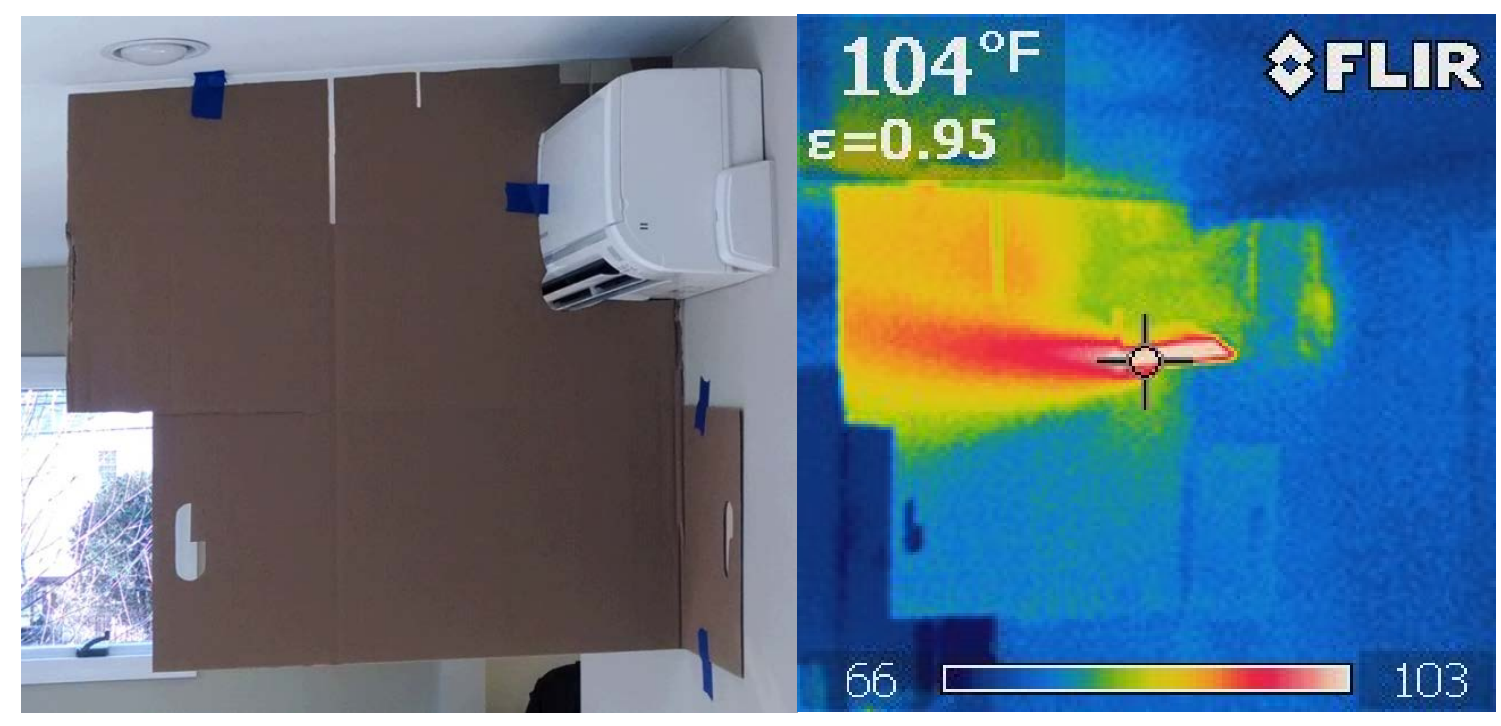

Figure 37. Visible and infrared images of DHP operation

High return air temperature was not an issue that CARB had considered before this monitoring project. DHP fan coils are nearly always mounted high on walls for two ostensible reasons:

- They are above head height and out of the way of furniture, etc.

- Initially DHPs were used mostly for cooling where a high wall placement will improve performance.

While locating fan coils lower on walls may not be practical, return air temperature may be a good factor to consider when selecting and installing DHPs.

\subsubsection{Defrost}

While details of defrost control algorithms are not public, after discussions with manufacturers, CARB learned that a defrost cycle is initiated by the presence of a sufficiently cold coil temperature for a specific length of time. Defrost terminates once the coil warms to a certain temperature (which occurs very quickly if no frost is present on the coil). The number and duration of defrost cycles, therefore, is generally a function of outdoor air temperature, humidity, and heat pump output.

The location of the outdoor unit can also have some effect on defrost frequency. If a unit is installed where water or melting snow or ice can drip onto it, ice is very likely to form on the evaporator coil. The heat pump in Figure 38 was installed beneath a deck. Although out of direct weather, as snow and ice melted on the deck, water would drip down onto the heat pump and refreeze. CARB observed other instances where two (or more) heat pumps that were installed vertically had defrost problems. For example, when the upper heat pump in Figure 39 defrosted, water would drip onto the lower heat pump. When testing performance of the lower unit, CARB found the system entered defrost mode every 10 minutes. 


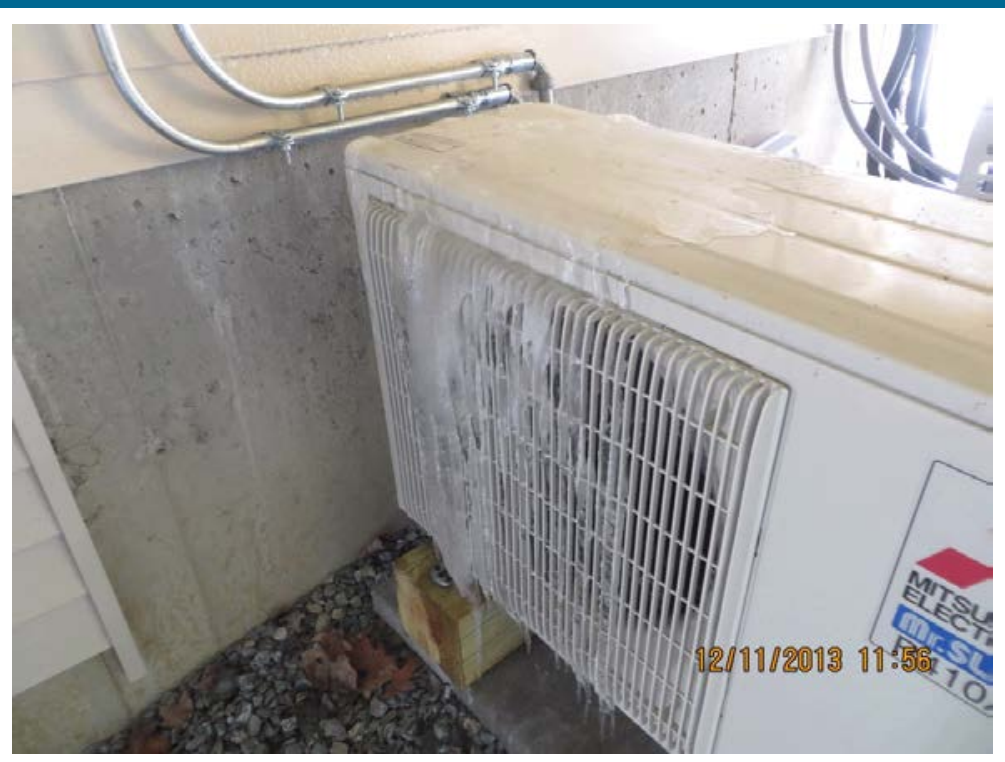

Figure 38. Snow melting from deck above causes icing and excessive defrost on this heat pump (not one of the units monitored for this study)

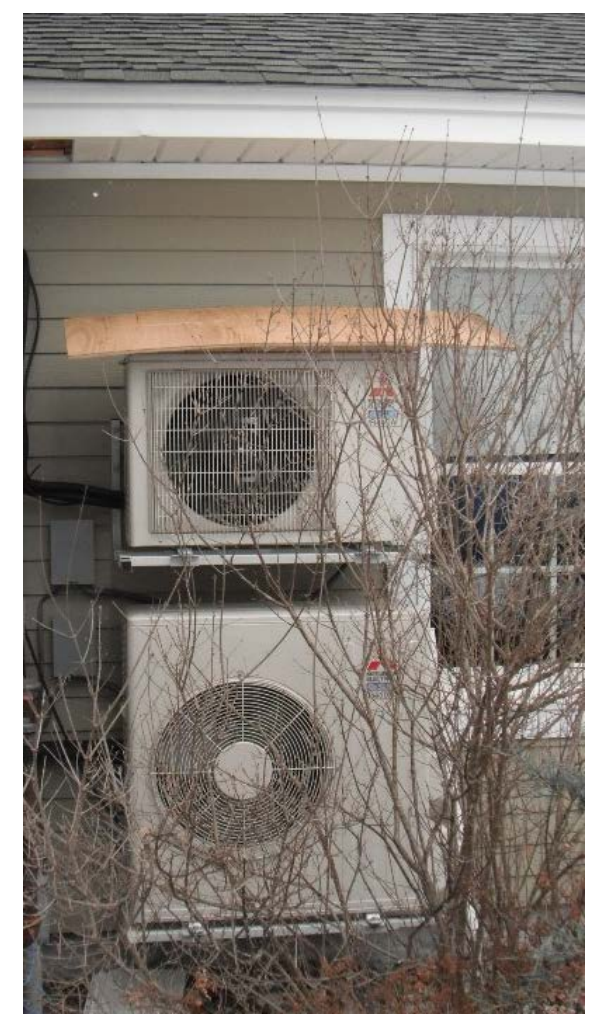

Figure 39. Heat pumps at Site 8. During short-term testing, the lower unit entered defrost mode every 10 minutes; CARB suspects this was largely a result of defrost water from the upper unit refreezing on the lower unit

While defrost should certainly be minimized for best performance, CARB did not find that excessive defrosting dramatically impacted overall efficiency of any heat pump monitored. Table 
8 shows seasonal COP values with and without defrost cycles included. These COP values were calculated by removing data during defrost cycles as discussed in Section 3.2.3 above.

Table 8. Overall COP With and Without Defrost Cycles Included

\begin{tabular}{c|c|c|c}
\hline Site & Overall COP & COP w/o Defrost & Days Monitored \\
\hline $\mathbf{1}$ & 1.61 & 1.69 & 204 \\
$\mathbf{2}$ & 1.99 & 2.01 & 141 \\
$\mathbf{4}$ & 2.31 & 2.44 & 142 \\
$\mathbf{5}$ & 1.71 & 1.73 & 28 \\
$\mathbf{8}$ & 2.33 & 2.41 & 44 \\
$\mathbf{9}$ & 1.11 & 1.12 & 57 \\
$\mathbf{1 0}$ & 2.06 & 2.11 & 51 \\
\hline
\end{tabular}

\subsubsection{Thermostat Setback}

In this study CARB did not assess setback strategies in detail, but several sites did use programmable thermostats to lower set points over the course of the day. Site 1 employed a setback strategy where set point was reduced from midnight to 6 a.m. and from 10:30 a.m. to 5 p.m. An example of data from this site is shown in Figure 40. When the unit turned back on following a setback period, the compressor often operated at high speed to recover. While having the heat pump off during setback periods will certainly save energy, the unit operates with lower efficiency during recovery.

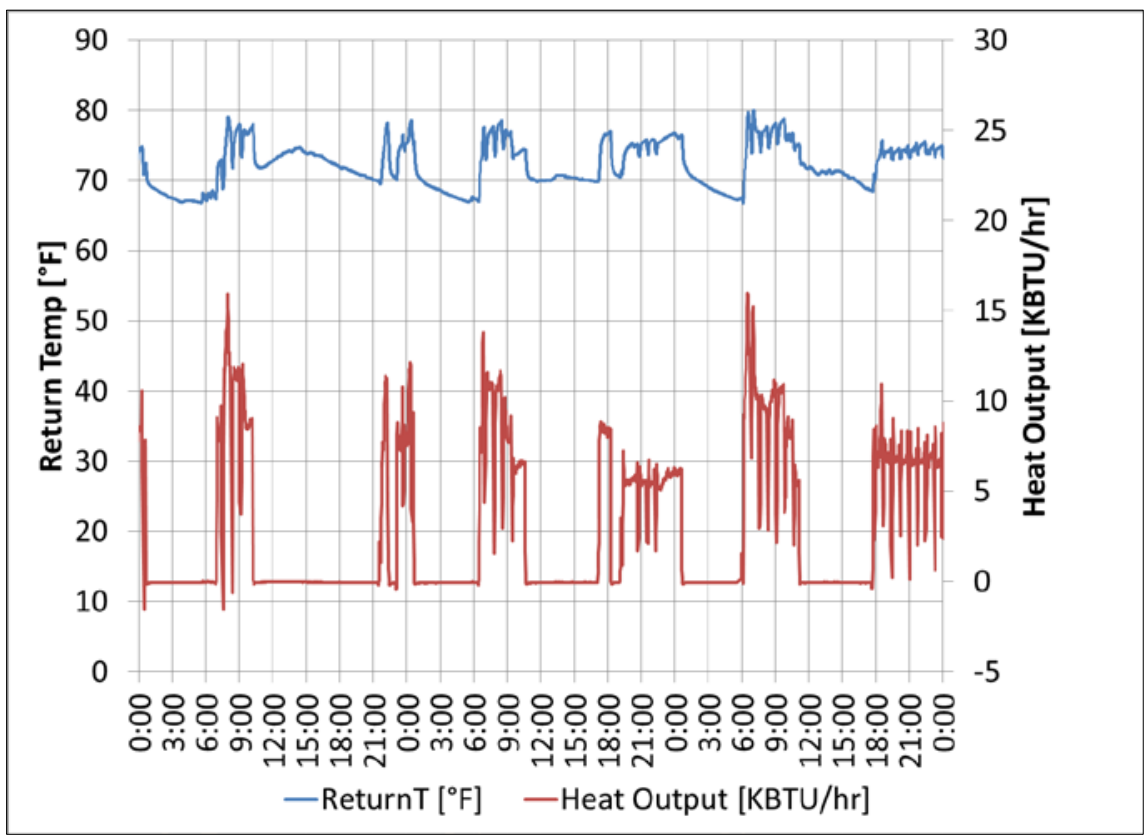

Figure 40. Setback strategy over 3 days in February 2014 at Site 1

In the period shown in Figure 41, setback occurs from 12:40 a.m. to 6:20 a.m. Shortly after the unit begins to recover at 6:20 a.m., heat output spikes to $13,000 \mathrm{Btu} / \mathrm{h}$ and COP is 2.15 . As the indoor temperature gets closer to set point, the unit modulates down to $6,500 \mathrm{Btu} / \mathrm{h}$ and COP levels off at 3.0. This demonstrates that recovery from setback certainly can lower the seasonal 
COP of the system. Nevertheless, there are likely electricity savings to be achieved from operating the unit infrequently (or at lower capacity) at night and during the day. It is unclear if the oil heating system in this home operated during setback periods.

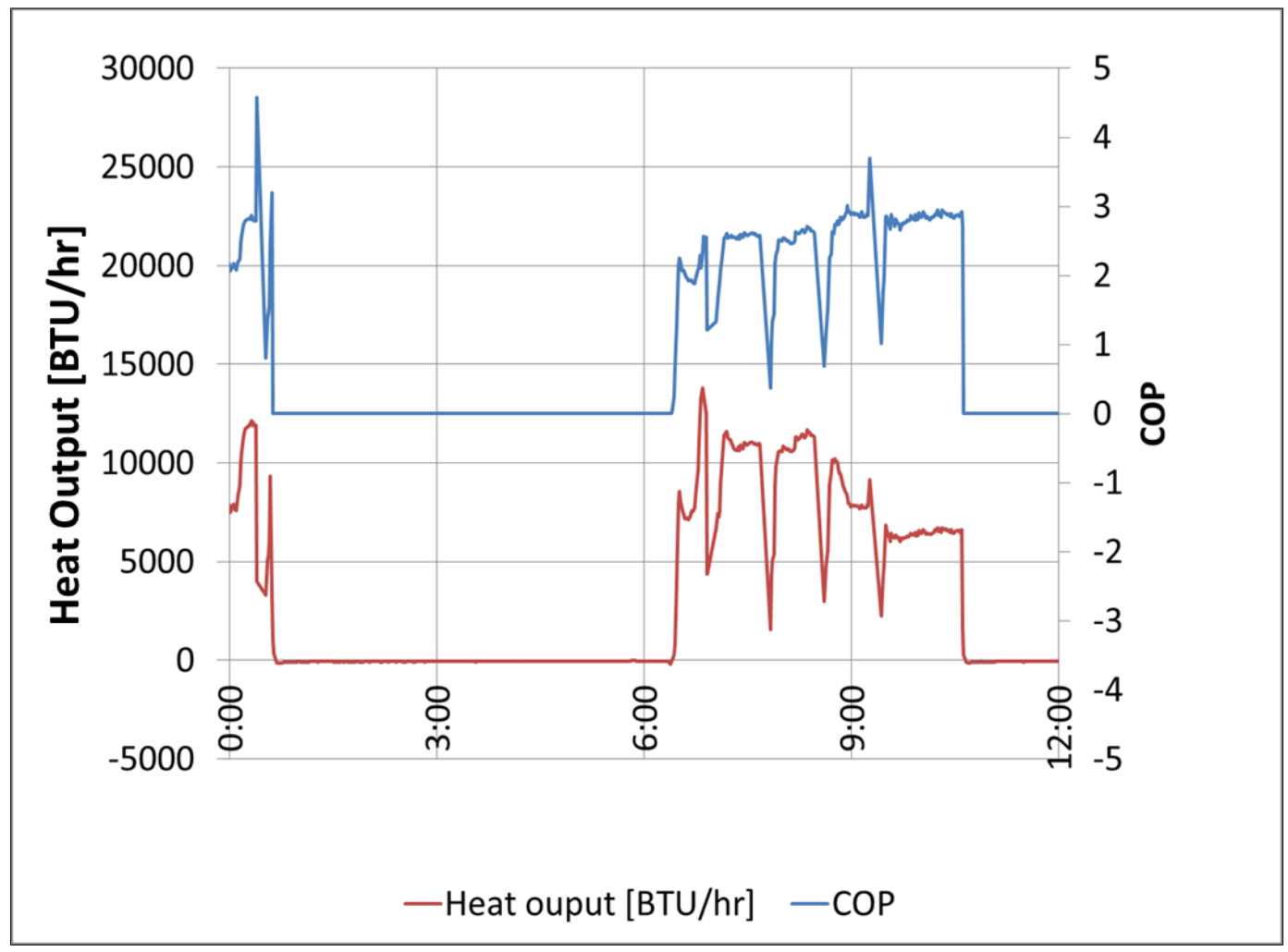

Figure 41. Example of recovery from setback at Site 1

\subsubsection{Fan Speed}

Most heat pump models adjust fan speed automatically ("auto" mode) but also allow the user to select a fan speed manually. While CARB cannot monitor control settings, CARB was able to ascertain fan speed. It appears that all but two homeowners in this study left the fan on "auto"; Site 1 and Site 9 were the exceptions. These heat pumps remained in low fan speed for the entire monitoring period. As a result, the heat output remained low even though the unit delivered higher supply temperatures. Site 9 had the lowest overall COPs across the entire data set. CARB believes that the low fan speed at Site 1 was one of the key reasons the seasonal COP was much lower than the FE18 at Site 4 (which is in a slightly colder climate). As indicated in NREL's lab study, high compressor frequencies coupled with low fan speeds are known to significantly reduce COP (Christensen et al. 2011).

CARB believes this should be evaluated in more detail. If there are consistent findings showing that low fan speed settings can dramatically reduce capacity and efficiency, these limitations should be made clearer to contractors and users.

\subsubsection{Cycling}

Inverter-driven compressors can achieve high efficiencies because they have the ability to modulate output to match the heating load. However, when the load drops below the system's 
minimum capacity, cycling can occur. Cycling is known to have detrimental effects on the efficiency of these units (Christensen et al. 2011).

At Site 2, a highly insulated Passive House that utilized the DHP as the only heating source, the DHP began to cycle when the outdoor temperature exceeded $40^{\circ} \mathrm{F}$. This trend is clear in Figure 13 in the Results section; COP actually drops at higher temperatures when more cycling occurs. This home had a design load of $6 \mathrm{kBtu} / \mathrm{h}$ and a 1-ton system was installed (Mitsubishi FE12). Figure 42 displays the power consumption during one of these periods of modest loads (in April 2014). At these conditions ( $\mathrm{ODB}=55^{\circ} \mathrm{F}$, indoor dry bulb $=72^{\circ} \mathrm{F}$ ), the system's capacity was limited at approximately $5,000 \mathrm{Btu} / \mathrm{h}$. These operating conditions translated to a COP of 1.41 for the day.

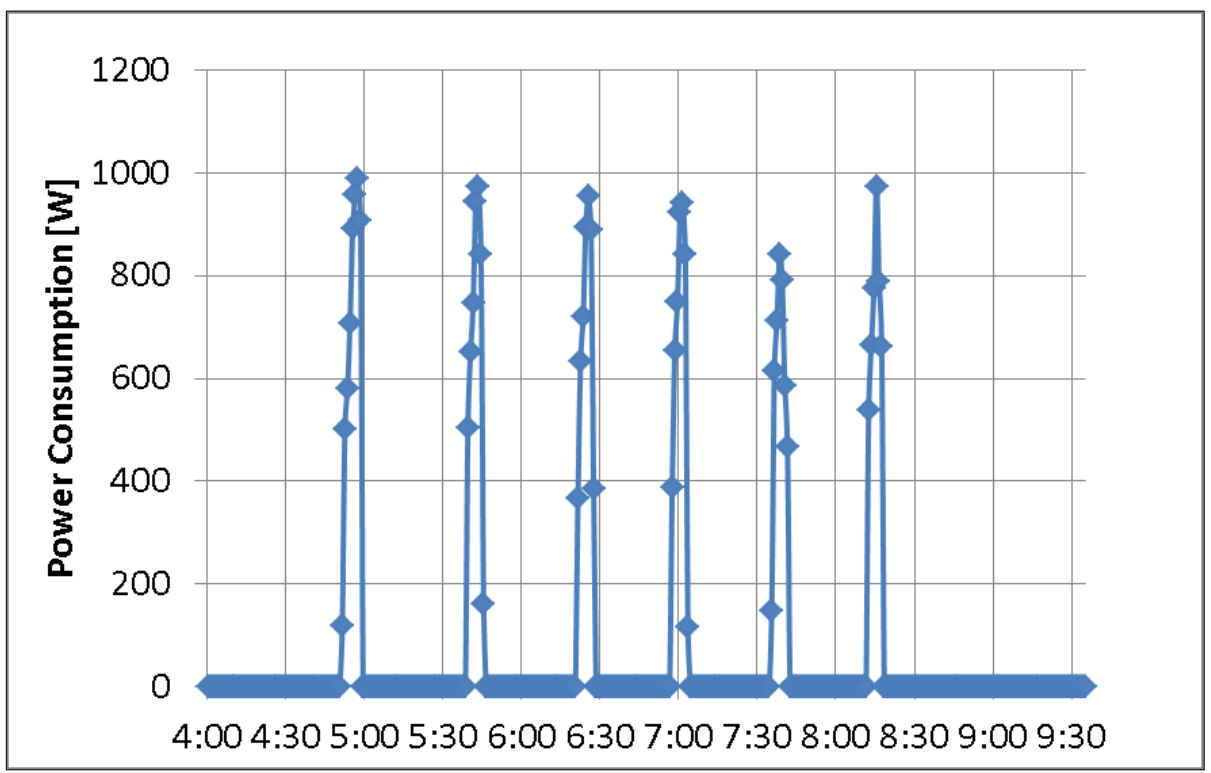

Figure 42. Cycling during low load conditions at Site 2. Each point represents 1 minute; this is the only time the heat pump operated during this early spring day

\subsection{Operating Costs Compared to Other Fuels}

An important barrier to large-scale adoption of DHPs in cold climates lies in their operating costs compared to other heating options. Operating costs were calculated for the monitoring periods of the three sites with the largest data sets: 1,2, and 4. A summary of the data used in this cost analysis is shown in Table 9.

Table 9. Cost Data Monitoring Summary

\begin{tabular}{c|c|c|c}
\hline & Site $\mathbf{1}$ & Site 2 & Site 4 \\
\hline Total Heat [kBtu] & 12,021 & 5,454 & 34,924 \\
\hline Total Electricity [kWh] & 2,183 & 974 & 4,425 \\
Monitoring Start & $11 / 8 / 2013$ & $1 / 9 / 2014$ & $12 / 3 / 2013$ \\
\hline Monitoring End & $5 / 31 / 2014$ & $4 / 30 / 2014$ & $4 / 30 / 2014$ \\
\# of Days Monitored & 204 & 111 & 148 \\
\hline
\end{tabular}


Using electric energy consumption values from Table 9, an operating cost comparison was generated for four heating methods: heat pump, electric resistance, oil, propane, and natural gas (calculated with $85 \%$ efficiency). These costs, which are based on average New England utility rates (Table 10), are shown in Table 11.

Table 10. Average New England Utility Rates

\begin{tabular}{c|c}
\hline Heating Fuel & Rate \\
\hline Oil & $\$ 4.16 / \mathrm{gal}$ \\
\hline Propane & $\$ 3.85 / \mathrm{gal}$ \\
Electricity & $\$ 0.18 / \mathrm{kWh}$ \\
Natural Gas & $\$ 1.45 /$ therm \\
\hline
\end{tabular}

Table 11. Operating Cost Increases (Decreases) of Other Heating Systems Compared to ASHPs During the Monitoring Period

\begin{tabular}{c|c|c|c}
\hline Heating Method & Site 1 & Site 2 & Site 4 \\
\hline Heat Pump & $\$ 386$ & $\$ 172$ & $\$ 783$ \\
\hline Electric Resistance & $61 \%$ & $64 \%$ & $131 \%$ \\
Oil (85\% efficiency) & $10 \%$ & $12 \%$ & $58 \%$ \\
\hline Propane (85\% efficiency) & $53 \%$ & $56 \%$ & $120 \%$ \\
Natural Gas (85\% efficiency) & $(47 \%)$ & $(46 \%)$ & $(24 \%)$ \\
\hline
\end{tabular}

For electric resistance, oil, and propane, values are displayed as the percentage increase over the heat pump's operating cost (to produce the same amount of heat that was measured from the heat pump). It is important to note that these are only costs for the monitoring period, not the entire heating season. Additionally, this analysis does not consider installation/equipment costs. This is a simplified analysis for academic purposes that neglects duct losses, additional fan and pump power, cycling and part-load effects of fuel systems, etc. For electric resistance, total system efficiency is assumed to be $100 \%$, while combustion heating systems are analyzed with an overall efficiency of $85 \%$. Table 11 suggests, for example, that using an $85 \%$-efficient oil system at Site 1 would have cost approximately $10 \%$ more than using the heat pump.

Table 12 shows an array of COPs where heat pump would have equivalent operating costs as various fossil fuel heating types: oil, propane, natural gas. This chart was assembled from average New England utility costs. This is an oversimplified analysis for reference purposes only. The numbers below are simply based on overall efficiency and do not include factors such as auxiliary electric use (for fans, pumps, etc.).

Based on results from this research, a majority of monitored units are performing at COPs that give them a lower operating cost than available from oil or propane. The heat pumps monitored would cost more to operate than natural gas systems. It is important to note that these COP switchover points will vary based on utility costs and climate. 
Table 12. Equal-Cost COP Values Based on New England Utility Rates

(EIA2014a and EIA2014b)

\begin{tabular}{c|c|c|c}
\hline Efficiency & Oil & Propane & Natural Gas \\
\hline $\mathbf{8 0 \%}$ & 1.38 & 0.92 & 2.75 \\
$\mathbf{9 5 \%}$ & 1.63 & 1.09 & 3.24 \\
\hline
\end{tabular}

\subsection{Further Testing and Evaluations}

The results from this monitoring effort are enlightening, but CARB's key conclusion is that more investigation is needed. The results from this monitoring effort show a wide range of performance with many systems performing below expectations. More work is needed to better assess energy consumption and capacities of these systems in different climates and home configurations. CARB hopes to streamline this evaluation method and implement it across a wider range of systems and homes.

One other possible evaluation method is electric coheating. Coheating is a well-known method for characterizing a heat pump COP by comparing energy consumption to electric resistance at similar loads. Now that several months of heating performance data have been collected, CARB is pursuing a coheating test at Site 2 for the 2014-2015 heating season. This location allows for an ideal monitoring setup as it has very low loads (design load less than $6,000 \mathrm{Btu} / \mathrm{h}$ ) and will require only one or two electric resistance heaters. The electric heaters chosen can be fanassisted and mounted in a similar orientation to the heat pump. While this is only a test of a single system, comparison of results from the two test methods may be enlightening and worth repeating. 


\section{Conclusions}

Answers to the research questions addressed by this study are outlined below.

What heating output, electric use, and COP do these ASHPs deliver?

CARB observed overall COPs ranging from 1.1 to 2.3. Some systems were seen to deliver heat in line with maximum listed capacities; others did not. The likely reasons for poor lower capacities and efficiencies are addressed below.

It was only at Site 4 that the heat pump was consistently operated at maximum capacity. The heat pump was the only source of heat in this Vermont home, and it was seen to deliver 15,000 Btu/h at $-15^{\circ} \mathrm{F}$, very similar to the capacity provided by the manufacturer. At most other sites, heat pumps were operated as supplemental heat sources. In very cold conditions, auxiliary systems provided most (or in some cases all) of the heating.

Site 2 was a Passive House where the heat pump was the sole source of heat, but the 1-ton heat pump was oversized for the $6,000-\mathrm{Btu} / \mathrm{h}$ design load. The heat pump here was not seen to provide more than 5,000-6,000 Btu/h.

How do these vary with outdoor temperatures and loads?

All heat pumps were seen to provide useful heating at subzero (Fahrenheit) temperatures, but the capacity and efficiency varied significantly from site to site (even between sites with the same model heat pump). At Site 4, for instance, a Mitsubishi FE18 operated at COPs of 1.5-2.0 at outdoor temperatures of $-10^{\circ} \mathrm{F}$. The FE18 at Site 1, by contrast, operated at COPs of 1.0-1.2 at outdoor temperatures between $0^{\circ} \mathrm{F}$ and $5^{\circ} \mathrm{F}$.

The key reasons for these differences are: likely higher return air temperatures at Site 1, the fan speed at Site 1 was manually set at low speed (limiting capacity and efficiency), and use of a frequent setback control strategy.

How does cycling affect efficiency during mild outdoor conditions?

At Site 2, where the heat pump was oversized for the very small load, the heat pump cycled often. Daily COP peaked when average outdoor air temperatures were near $40^{\circ} \mathrm{F}$. At average daily temperatures higher and lower than $40^{\circ} \mathrm{F}$, COPs drop. When the unit was able to modulate without cycling at outdoor air temperatures of $40^{\circ} \mathrm{F}$, it was common to see daily COPs near 2.5. When average outdoor air temperature rose above $50^{\circ} \mathrm{F}$, frequent cycling resulted in COPs near 1.5 .

How do varying thermostat set points affect efficiency (e.g., frequent setup and setback may lead to higher operating speeds and lower efficiencies)?

Site 1 was the only site where a rigorous setback strategy was applied. At Site 1, it was common to see a spike in energy consumption (and drop in COP) when the heat pump was recovering from setback. It is believed the setback strategy still reduced electricity consumption, but frequent recovery did result in lower overall COPs. 
What level of savings can be expected over other fuels?

While the measured COPs of systems in this study are lower than those of other studies, most of the systems still provided operating cost savings over oil, propane, or electric resistance heating. Table 13 shows operating cost increases that could be expected (compared to the ASHP) at the three sites with the most complete data. None of the ASHPs monitored would have provided operating cost savings over an efficient natural gas heating system.

Table 13. Operating Cost Percent Increase (Decrease) Compared to Heat Pump During the Monitoring Period

\begin{tabular}{c|c|c|c}
\hline Heating Method & Site 1 & Site 2 & Site 4 \\
\hline Heat Pump & $\$ 386$ & $\$ 172$ & $\$ 783$ \\
Electric Resistance & $61 \%$ & $64 \%$ & $131 \%$ \\
Oil (85\%) & $10 \%$ & $12 \%$ & $58 \%$ \\
Propane (85\%) & $53 \%$ & $56 \%$ & $120 \%$ \\
Natural Gas (85\%) & $(47 \%)$ & $(46 \%)$ & $(24 \%)$ \\
\hline
\end{tabular}




\section{References}

Baylon, D.; Larson, B.; Storm, P.; Geraghty, K. (2012). Ductless Heat Pump Impact \& Process Evaluation: Field Metering Report. Seattle, WA: Ecotope for the Northwest Energy Efficiency Alliance. Accessed November 2, 2013. http://neea.org/docs/default-source/reports/ductless-heatpump-impact-process-evaluation-field-metering-report.pdf.

Bugbee, J.; Swift, J. (2013). Cold Climate Ductless Heat Pump Performance, Energy Engineering, 110:2, 47-57.

Christensen, D.; Fang, X.; Tomerlin, J.; Winkler, J.; Hancock, E. (2011). Field Monitoring Protocol: Mini-Split Heat Pumps. Golden, CO: National Renewable Energy Laboratory. Accessed November 2, 2013. http://www.nrel.gov/docs/fy11osti/49881.pdf.

EIA (2014a). "Weekly Heating Oil and Propane Prices (October - March)." Washington, DC: U.S. Energy Information Administration. Accessed September 15, 2014. http://www.eia.gov/dnav/pet/pet_pri_wfr_dcus_svt_w.htm.

EIA (2014b) "Average Retail Price of Electricity to Ultimate Customers by End-Use Sector (June 2014 YTD).” Washington, DC: U.S. Energy Information Administration. Accessed September 15, 2014. http://www.eia.gov/electricity/monthly/epm table_grapher.cfm?t=epmt_5_06_b

(ICC) (2009). 2009 International Energy Conservation Code. International Code Council. Accessed at http://publicecodes.cyberregs.com/icod/iecc/2009/. Accessed March 23, 2015.

Johnson, R.K. (2013). Measurement Performance of a Low Temperature Air Source Heat Pump. DOE/GO-102013-3788. Golden, CO: National Renewable Energy Laboratory. Accessed October 21, 2013. http://apps1.eere.energy.gov/buildings/publications/pdfs/building_america/low temp_air_ source heat pump.pdf.

KEMA Inc. (2009). Ductless Mini Pilot Study: Middletown, CT. Accessed March 23, 2015. http://library.cee1.org/sites/default/files/library/8723/CEE Eval_2009DuctlessMiniPilotSt udyFinalReport 1Jun2009.pdf

Mitsubishi Electric US, Inc. (2013). Submittal Data: MSZ-FE12NA-8 \& MUZ-FE12NA1. Accessed March 23, 2015. http://usa.mylinkdrive.com/uploads/documents/1642/document/MSZFE12NA-MUZ-FE12NA Submittal.pdf.

NEEP (2013). Northeast/Mid-Atlantic Air-Source Heat Pump Strategy Report. Lexington, MA: Northeast Energy Efficiency Partnerships. Accessed November 11, 2014. http://www.neep.org/sites/default/files/resources/NortheastMid-Atlantic\%20AirSource $\% 20$ Heat $\% 20$ Pump $\% 20$ Market $\% 20$ Strategies $\% 20$ Report_0.pdf.

Winkler, J. (2011). Laboratory Test Report for Fujitsu 12RLS and Mitsubishi FE12NA MiniSplit Heat Pumps. DOE/GO-102011-3380. Golden, CO: National Renewable Energy Laboratory. Accessed October 2, 2014.http://www.nrel.gov/docs/fy11osti/52175.pdf. 


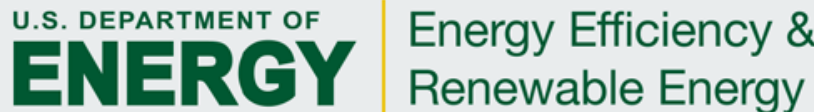

